NBER WORKING PAPER SERIES

\title{
GENDER WAGE GAPS AND WORKER MOBILITY: EVIDENCE FROM THE GARMENT SECTOR IN BANGLADESH
}

\author{
Andreas Menzel \\ Christopher Woodruff \\ Working Paper 25982 \\ http://www.nber.org/papers/w25982 \\ NATIONAL BUREAU OF ECONOMIC RESEARCH \\ 1050 Massachusetts Avenue \\ Cambridge, MA 02138 \\ June 2019
}

The data used in this paper were collected from garment factories in Bangladesh as a part of several projects. We thank the UK Department for International Development-Economic and Social Research Council Growth Research Programme, the Growth and Labour Markets in Low Income Countries Programme, the International Growth Centre, and the Small and Medium Enterprises Program at Innovations for Poverty Action (IPA) for funding of projects that enabled the collection of the data. Funding for the analysis was also provided by the European Research Council Advanced Grant 669746 (RMGPP). We thank Chris Burningham for research assistance and seminar participants at PSE, Oxford, Michigan, CERGE- Prague, ESMT- Berlin and Yale for comments. Errors remain our own. The views expressed herein are those of the authors and do not necessarily reflect the views of the National Bureau of Economic Research.

NBER working papers are circulated for discussion and comment purposes. They have not been peer-reviewed or been subject to the review by the NBER Board of Directors that accompanies official NBER publications.

(C) 2019 by Andreas Menzel and Christopher Woodruff. All rights reserved. Short sections of text, not to exceed two paragraphs, may be quoted without explicit permission provided that full credit, including (C) notice, is given to the source. 
Gender Wage Gaps and Worker Mobility: Evidence from the Garment Sector in Bangladesh Andreas Menzel and Christopher Woodruff

NBER Working Paper No. 25982

June 2019

JEL No. J16,J31,O14

\begin{abstract}
Data from 70 large export-oriented garment manufacturers in Bangladesh show that gender wage gaps are similar to those found in higher-income countries. Among production workers, women's wages are 8 percent lower. We show that by combining short administrative panels, survey data from a representative sample of workers, and structure, we can estimate how the wage gap evolves over workers' careers. Gender differences in internal and across-factory promotions contribute roughly equally to the emergence of the gender gap over worker careers. Differences in promotion rates appear to arise mainly from career concerns rather than frictions coming from household responsibilities.
\end{abstract}

Andreas Menzel

CERGE EI

Politickych Veznu 7

11121 Prague

Czech Republic

Andreas.Menzel@cerge-ei.cz

Christopher Woodruff

Queen Elizabeth House

University of Oxford

OX1 3TB

UK

and NBER

christopher.woodruff@qeh.ox.ac.uk 


\section{Introduction}

A bourgeoning literature seeks to determine the underlying causes of gender pay gaps in various settings (Blau and Kahn, 2017). The explanations of the gaps can be broadly classified into three strands. First, different preferences of women and men may lead them to make different job choices, or to behave differently on the job, affecting output and pay (Cook et al. 2018, Azmat and Ferrer 2017, Flory et al. 2015). Second, even if preferences do not differ, women may be subject to different constraints on their ability to maximize output on the job due to, for example, household and family demands (Goldin et al. 2014, Bertrand et al. 2010, Corcoran et al. 2005). These constraints may also result in lower mobility across employers, giving employers monopsony power in labor markets to reduce wages (Black 1995, Manning 2013), or preventing women from sorting to better-paying employers to the same extent as men (Card et al. 2016). And third, the gaps may reflect outright discrimination, in terms of lower evaluations of objectively equal output (Sarsons 2017, 2019, Egan et al. 2017, Mengel et al. 2018, MacNell et al. 2015, Hengel 2018, Card et al. 2018, Goldin and Rouse 2000). ${ }^{1}$

The literature also increasingly focuses on the dynamics of wage gaps over workers' careers. Wage gaps are found to increase, both in absolute and relative terms, with worker age. As much as 40 percent of the widening of the gap is due to men being more likely to move to employers that pay more on average (Barth et al. 2019, Goldin et al 2017, Bronson and Thoursie 2019, Albrecht et al. 2018). The remaining increase is due to men realizing faster wage growth within employers, or reaping higher wage increases when moving between employers that pay their average workers similarly.

However, most of the literature on the static and dynamic gender pay gap is based on data from high-income countries. Evidence from developing countries is much sparser. This owes in large part to the lack of high-quality data in developing countries. Nevertheless, we may expect gender wage gaps to be as prevalent in developing countries. Indeed, many of the related potential drivers, such as norms, preferences and expectations, are even more pronounced in many developing countries (Jayachandran 2015, Giuliano 2017).

\footnotetext{
${ }^{1}$ A variant of this form of discrimination is worse evaluation of objectively similar behavior, for example in wage negotiations, where the same level of assertiveness has been shown to result in poorer evaluations and more severe penalties for women (Bowles et al. 2007).
} 
We address the data issue by using administrative records for more than 80,000 workers from 70 large garment factories in Bangladesh. The salary data come from electronic wage records of the factories, and are therefore measured with minimal error. $^{2}$ We use the data to make two contributions to the literature. First, we show that the wage gap in these data is quite similar to that found in the large literature from higher-income countries, though we find less evidence for a crucial role of motherhood in explaining the wage gap. Our second contribution is methodological. While recent literature from higher-income countries uses data that allow tracking of individual workers across time, we show that data from individual employment spells can be combined with data from worker surveys to decompose the wage gap into the parts arising from wage growth within factories, and from moving across factories. This allows us to make a more complete decomposition of the gender wage gap than is possible from direct analysis of our data. We view this as particularly important for lower-income countries, where data tracking workers across employers are absent.

Among non-managerial workers, the data show an overall wage gap of around 8 percent, very similar to that found in high-income countries (Blau and Khan, 2017). All workers in our sample entered the garment sector at the same entry-level position and wage. Thus, the wage gap in the cross section of workers emerges over time as wage growth for women and men diverges, and as male workers stay longer in the sector. Our data track workers only within their current factory, and around 5 percent of all male workers, and 4 percent of all female workers in our sample switch factories each month. ${ }^{3}$ Anecdotal evidence indicates that these movements often come with significant wage increases. Because we do not follow workers when they move to a different factory we cannot observe directly the salary increases that occur through movement

\footnotetext{
2 Several papers have examined wage gaps using household surveys in countries with large garment sectors. See Huynh (2016) for an analysis of nine Asian countries, including Bangladesh, and Abras (2012) for an analysis of Bangladesh, India, Pakistan and Vietnam. Both Abras (2012) and Huynh (2016) find positive wage gaps for women in the sector. It is unclear why the household data should be so different from our factory data.

3 These high mobility rates are consistent with evidence from export manufacturing sectors in other developing countries. In an experiment among five Ethiopian factories, Blattman and Dercon (2018) find that 77 percent of new hires in unskilled factory jobs leave the factories again within one year of employment. A series of reports by the garment sector consultancy Impactt reports monthly exit rates of garment workers of 7-12 percent in Chinese, Bangladeshi and Indian factories (Impactt 2011, 2012, 2013). Further research by consultancies indicates monthly turnover rates of 15 percent and higher in Chinese export-oriented electronics factories (AT Kearney 2014, KPMG 2013). Boudreau et al. (2019) use retrospective labor histories to show that garment workers in Bangladesh tend to move to factories with perceived better working conditions but lower salaries.
} 
across factories, and hence, we cannot directly observe total wage growth. However, by adding information from worker surveys and some structure, we can back out the total rate of wage growth and decompose it into the share associated with movement across factories and promotions within factories.

We find that that men move more quickly out of entry-level positions. As a result, their wages grow around 60-70 percent faster at the earliest stages of their career. The faster initial progression of men is explained almost equally by faster rates of internal and external promotion (from switching between factories). At later stages of workers' careers, almost all wage growth is internal, and wage growth is not significantly different for women and men. Thus, the gender wage gap widens in the first years workers spend in the sector and levels off towards the end of their careers. Averaged over the careers, movement across factories accounts for around 40-50 percent of wage growth for both females and males. Cross-factory promotion is concentrated at early stages of workers' careers, resembling established findings from the United States (Topel and Ward 1992). In contrast to some of the literature from higher-income countries, we find little evidence of sorting across employers in this sector; if anything, men are more likely to work at factories that pay less on average, though this difference is not statistically significant. Our results resemble those of the only other study we are aware of that decomposes wage growth of Swedish men and women into the three components of within-employer wage growth, dynamic sorting to better-paying employers, and wage growth from moving between employers conditional on their average pay (Albrecht et al. (2018)). ${ }^{4}$

We next turn to exploring the drivers of wage gaps, using a rich set of worker observables obtained from factory records and surveys of a representative sample of workers. From 16 factories we have detailed data on individual worker skills and productivity. We show that differences in skills explain around 40-50 percent of static wage gaps and differences in internal promotion frequencies at these factories.

Household and family constraints have been shown to be important drivers of the gender gap in a number of high income countries (Kleven et al. 2018, 2019). However,

\footnotetext{
${ }^{4} \mathrm{~A}$ number of other studies have looked at the relative contribution of within-employer wage growth, and wage growth from moving between employers, on the evolution of the wage gap across average worker careers. These studies have typically used longitudinal worker surveys and have found a sizeable contribution from movement between employers, e.g. Loprest (1992) for the U.S., Hospido (2009) for Spain, or Del Bono and Vuri (2011) for Italy,. Many find that men move more often and also obtain larger wage increases when they move.
} 
our survey data suggest that these factors play less of a role in this setting. Specifically, wage levels, wage growth, and the rate of movement between factories of married female workers or of female workers with children do not differ significantly from those of unmarried or childless women. On the other hand, we find some evidence for married men having higher pay growth and higher rates of movements across factories than unmarried men, resembling the results from an older literature from high income settings on the male marriage boost in labor market outcomes (for recent summaries of this literature see Linde Leonard and Stanley, 2015, and Sobel, 2012).

Given either more aggressive bargaining by males or discrimination against women, we would expect to find that the skills of promoted men are lower than the skills of promoted women. Instead, our skills data show the opposite: conditional on the pay grade of the workers, male workers are more skilled. The story the data tell is consistent with men acquiring skills faster, and exploiting more opportunities for personal advancement from moving across factories. Faster skill acquisition by males may still be driven by discrimination through any of several channels. First, factories may invest more in men, offering them more training on new skills. Second, women in the sector are very rarely promoted to supervisory roles, beyond the positions studied in this paper, a more common career path for their male colleagues. Survey data suggest no differential investment in training. Indeed, surveyed female workers are more likely to report receiving opportunities to increase their skills, though the difference is not statistically significant. With regard to promotion to supervisory positions, the strong glass-ceiling in the sector between ordinary and supervisor positions could induce women to invest less in their skills and in promotions (Macchiavello et al., 2016).

Selection into and out of the sector is a concern for studies of the gender pay gap, particular those like ours that focus on a particular sector in the economy. Using census data, Figure 1 shows that among male garment workers, average education rates coincide with average education rates from the last Bangladeshi census in 2011, not just in the cross section, but also for men of different ages. For women, average education rates are slightly below average rates from the census for the different birth cohorts, though the differences are minimal. We also find that controlling for education, age, marital status or children has little effect on the estimated gender gaps in wages or wage growth. 
Regarding selection out of the sector, our survey data show that men who make it to the highest operator pay grade during their career are slightly more selected than women in terms of education, with the gender difference being marginally statistically significant. This suggests that differential selection out of the sector may play a role in the emergence of the pay gap, though we note again that our estimated wage gaps are not materially affected by controlling for education, marital, or parental status.

The model we fit to the data also provides insight on the effect of how selection of those leaving the sector affects the estimated wage gap. Specifically, we are able to provide distributions of the highest pay grade that male and female workers entering the sector will reach during their career. This distribution will differ from crosssectional wage distributions if, for example, workers who end their career at lower pay grades exit the sector faster. We find, however, that the gender gap in this entry-stage distribution is only 1 percent larger than the average cross-sectional pay gap, consistent with selection out of the sector playing only a small role in the wage gaps.

Our main dataset consists of repeated monthly payroll records for all shop-floor workers from 70 garment export factories in Bangladesh. From the median factory we have 11 consecutive months of payroll data, allowing us to trace worker pay and worker jobs, including internal promotions within a factory over time. The factories are large, employing on average around 1,300 workers in the sewing section. ${ }^{5}$

To the best of our knowledge, this is the first study of gender wage gaps in a lowincome country using administrative wage data from employers. We believe the context is illuminating for other reasons as well. First, a large part of the literature on the gender wage gap emphasizes that as women's labor force participation increases, they enter sectors that evolved around male work preferences, espousing high levels of competitiveness (Flory et al. 2015), or rewards for working long and inflexible hours (Goldin 2014). By contrast, since its inception in the 1980s the Bangladeshi garment sector has employed large numbers of female workers, and is thus a "traditionally female" sector. Second, it has been argued that the lower prescribed attachment of women to the labor market causes lower investments into general and firm-specific human capital, and, thus, lower wages. The uniquely detailed skill data we collected in

\footnotetext{
${ }^{5}$ Beyond sewing-section workers, factories typically also employ cutting, finishing, knitting, or dyeing workers. To keep our sample of workers homogeneous across factories, we focus in this study on sewing section workers, who make up on average around 60 percent of the workers in the factories. The data we collected also exclude for management positions.
} 
the sector allow us to show that, at least in our setting, a wage gap is roughly equal parts investment in skills and maneuvering for promotions conditional on skill levels.

We begin by describing the data we use in the analysis in more detail. We next examine wage and grade gaps between the genders, first using the full administrative sample, and then the subsample of the data that allow us to control for the worker skills. We then introduce the model that allows us to back out external promotion and wage growth rates when workers move between factories. We then discuss the relative importance of external and internal promotion rates in driving the grade gap. We conclude by discussing evidence on how marriage and having children affect the differential internal and external promotion rates of men and women in the sector.

\section{Data}

The ready-made garment sector is the largest manufacturing sector in Bangladesh, accounting for 80 percent of Bangladesh's exports and around 12 percent of GDP. The sector employs 4 million workers, more than half of whom are women. With growth compounding at an annual rate of around 15 percent, the garment sector dramatically increased the share of women working in full-time wage jobs. We study workers in a sample of 70 large export-oriented Bangladeshi garment factories located in and around Dhaka, the larger of two major production areas in Bangladesh. All of the factories in our sample produce woven or light knit (e.g., t-shirts) garments. Production is typically organized into three sections: cutting, sewing, and finishing. ${ }^{6}$ The sewing sections employ around two-thirds of the workers in these factories, and around 80 percent of workers in the sewing sections are women. We focus on sewing-line workers for the remainder of the paper.

The factories in our sample are all direct suppliers of major European and American brands. They are largely locally owned and managed. Though information on the full distribution of factories in Bangladesh is limited, Figure 2 compares the factories in our sample with all factories registered through Accord and Alliance. ${ }^{7}$ The data indicate that our sample factories are mostly from the upper quartile of the distribution of

\footnotetext{
${ }^{6}$ Some factories in our sample have further sections, such as knitting, dyeing, or embroidery.

7 The Alliance for Bangladesh Worker Safety and the Accord on Fire and Building Safety in Bangladesh were both formed after the Rana Plaza factory collapse in 2013. These two organizations cover around 2,000 factories (roughly half of the factories active in the country) that are primary suppliers to Accord or Alliance buyers. Boudreau (2019) provides a more in-depth discussion of these two organizations.
} 
Bangladeshi factories by size. While the sample of factories is not representative of the full spectrum of firms in Bangladesh, our sample of workers has characteristics very similar to those in the only large-scale representative sample of which we are aware (Haque et al, 2015).

We draw data from three sources: administrative payroll records from the factory's human resources (HR) departments, surveys of randomly selected workers, and skills assessments of workers conducted by the industrial engineering departments of the factories. We briefly discuss each of these three types of data in turn.

\section{Payroll records}

We collected monthly payroll records from the factories. Each factory's data cover a period of at least six months, with a mean and median of 11 months. The data come from factories participating in various projects, with the earliest records from January 2012 and the latest from December 2017. The payroll records have one observation per worker-month and contain all workers employed by the factory for at least one day of the given month. For the majority of factories, our data are limited to the sewing sections and, for around half of the factories, to non-supervisory workers. These workers are classified by pay grades ranging from 7 (entry-level helpers) to 3 (highly skilled operators). The Bangladeshi minimum wage law for the garment sector proscribes a minimum wage for each worker grade, though workers on a given grade are often paid slightly more than the respective minimum level. Throughout the text we use the term "promotion" to represent a movement up in grades - for example from grade 5 to grade 4 . The monthly payroll records usually contain the worker's name, an ID number, the date the worker joined the factory, wages for regular hours, overtime earnings, some measure of absenteeism during the month, and a designation of the job performed by the worker. The factories in our sample have an average (median) of $1,294(1,072)$ sewing section workers. The smallest factory has 133 sewing workers and the largest around 4,400. In total, our data contain 144,500 individual sewing-line workers, 91,800 of whom are present in the data from the first month from each factory. ${ }^{8}$ In total, we have around 1.1 million observations at the worker-month level

\footnotetext{
${ }^{8}$ Our data do not allow us to track workers across different factories in our sample. Thus, we cannot rule out that some of the 144,500 unique workers are indeed the same person working at different factories in our sample. Our factories are a very small part of the industry, however, and they are geographically scattered, so we expect that this would be rare.
} 
from non-supervisory workers of grades 7 through 3 . In our sample, 81.5 percent of these sewing workers are female, a share that varies between 54.5 percent and 98.3 percent across the 70 participating factories.

The lowest grade (7) is assigned to unskilled, entry-level, workers. In the sewing section, these are typically referred to as "helpers" whose job is to cut thread or line up fabric for sewing operators. Workers operating sewing machines ("operators") are assigned to grades 6 through 3, with 6 being the lowest-skilled and 3 being the highestskilled operators. Sewing line supervisors, quality supervisors, and other lower-level supervisory staff are assigned grade 2, while higher-level managers are either assigned grade 1 or remain outside the grade scale. Essentially all workers in our sample entered the sector as a grade 7 worker and advanced to higher grades over time as they gain skills. The minimum wages in effect from December 2013 through the end of our data were around US\$65 per month for grade 7 workers (for 6 days per week of 8 hours) and around US\$85 for grade 3 workers. Overtime pay beyond 8 hours per day is paid 1.5 times the hourly rate implied by the minimum wage. Panel 2 in Table 1 shows the distribution of female and male workers in grades 7 through 3, indicating that men are overrepresented on higher grades.

The ability to track the same worker over the repeated rounds of monthly pay records within factories - crucial to identify internal promotion rates at the factories requires a reliable worker identifier. While all of our raw data contain worker ID numbers, we had to address two complications with the IDs. First, some factories reuse ID numbers from workers that have left the factory. Thus, more than one worker may have the same ID at different points in time. Second, some factories assign a new ID number when a worker is promoted to a new grade. Thus, the same worker can have more than one ID. One or the other of these problems arose in around 30 of the 70 factories in our sample. For these factories, we used worker-name and join-date combinations to assign a single unique identifier to each worker. In the very few (and arguably random) cases where this method yielded multiple workers with the same name and join-date in a factory, all observations with this name and join-date combination were dropped from the sample. ${ }^{9}$

\footnotetext{
${ }^{9}$ Some factories classify certain supervisory staff as grade 3 rather than grade 2 . We reclassified all workers with supervisory roles and with a lower grade to grade 2 . We also regraded a small number of workers listed at grade 8 (probationary) to grade 7 or grade 6 based on their designation (helper or
} 
The administrative records typically do not include the gender of the worker, so we use names to code the gender of each worker. Because some names may be either male or a female, we are not able to assign a gender to all of the workers. But we are able to assign a gender to 90 percent of all workers. We drop from the analysis those observations for which we are not able to designate a gender.

We use the payroll data to define variables for promotion and exit from the factory. A worker is promoted in month $t$ if her/his grade is higher in month $t+1$ compared with month $t .^{10} \mathrm{~A}$ worker is deemed to have exited if $\mathrm{s} / \mathrm{he}$ disappears from the data before the last month for which we have factory data. By these definitions, we find that the monthly promotion rate is around one percent, while the monthly exit rate is 4.9 percent. A naïve interpretation of the promotion rate implies that workers move up one grade every eight years, a rate of progression much lower than that implied by our survey data on sector experience and grade. We return to this issue below.

One potential issue with both of these measures is that we lack data on supervisors in 34 of the 70 factories. In these factories, workers promoted from lower grades to grade 2 or 1 will disappear from our dataset and will be recorded as having exited the factory rather than being promoted. In aggregate, we view it as a minor issue because promotion above grade 3 is a rare event. In the 36 factories for which we have supervisory data, only about 7 percent of all male (and 0.5 percent of female) promotions end with the worker in a supervisory grade or higher. Thus, given that we miss these promotions in roughly half our sample, 3.5 percent of all male promotions may not be recorded (and just short of 1 percent of male exits incorrectly recorded).

The salary records provide us with both wage and grade data, and we use both of these in the analysis. However, we note that wage and grade are not entirely independent of one another. A common practice in this sector is for the production staff, industrial engineers in particular, to determine an appropriate wage for a worker, and then for the human resources staff to set an appropriate grade conditional on that wage. We find it convenient to focus on wages for part of the analysis and on grades for another part. But the two should be viewed as co-determined.

operator). The number of these adjustments is small and all our results are robust to leaving out these grade-cleaning operations.

${ }^{10}$ We observe a small number of cases in which a worker appears to have been demoted. Most often, the worker soon reverts back to the previous grade. We assume in these cases that the initial demotion reflects a mistake by the factories. In the promotion analysis, we drop these few cases, though the results are not affected if we leave them in the data. 


\section{Skills assessments}

Production in all of our factories is organized on production lines, with each sewing operator performing a single stitch in the sequential production process. Almost all of the factories in our data employ industrial engineers who set an hourly target for each process (for example, a stitch or seam) required to complete the product. Each process is assigned a "Standard Minute Value" (SMV) which represents the number of minutes (or portion of a minute) a fully skilled and efficient worker would take to complete the task. The SMVs are usually based on international standards, but adjusted for factory conditions. For example, the SMV may be adjusted for the presence or absence of a helper, or quality of the machine (e.g., automatic thread cutting or not). Multiplying the inverse of the SMV by 60 gives the hourly expected output for the given process. The efficiency of a given sewing operator can then be measured as the number of times she completes the process divided by the expected output for that process. The efficiency is one measure of worker skill that factories care about.

Some processes are more complex or require skills that are rare among workers. These processes are referred to as "critical". Other processes require more physical strength. A worker's ability to perform more critical or physically demanding processes is also valuable to the factory. Factories also report that they value flexibility of an operator, that is, the number of processes or machines on which a given operator is skilled. For example, more flexible workers are able to step in to a wider variety of roles when workers are absent.

Some factories conduct regular skills assessments of operators, and we have collected the available assessments. ${ }^{11}$ We use the skills assessments to calculate four measures for each worker. First, we record the number of sewing processes on which a worker is tested as a measure of flexibility. Second, we measure the average efficiency of the worker on all skills tested. Third, an industrial engineer with substantial industry experience working for our project team coded the "criticality" of each process on a scale of one to seven. ${ }^{12}$ We create a variable which indicates the level of the most critical process on which the operator is tested. Last, our industrial engineer also flagged the

11 Most of these are from factories participating in a project implementing a consulting intervention which includes training on conducting regular skills assessments.

12 Some factories record processes as "A" (most critical), "B", or "C" (least critical). Our industrial engineer separated the A ratings into high-A, middle-A and low-A, and created similar tiers for the B ratings. In his judgment, the $\mathrm{C}$-rated processes were all of the same level of difficulty. This measure is highly negatively correlated with the target for the process, indicating that processes rated as more critical are more complex and take longer to complete. 
processes that require physical strength to complete. We create a variable indicating the worker is tested on at least one process requiring a high level of physical strength.

These four skills measures are, according to factories, highly correlated with the productivity of workers. The skills map more closely to the value of marginal product of a given worker than measures more commonly available in data, such as wages, providing a more precise control for productivity.

\section{Survey data}

In addition to the salary records and skills measures, we have survey data from a sample of randomly selected sewing machine operators in each of the factories. The surveys were conducted to support other projects. We collected both the worker name and the factory ID number for each respondent, and are able to match most of them to their payroll records. This yields a sample of 2,607 workers. The surveys contain several variables useful in our analysis: tenure in the garment sector, the number of factories the respondent has worked in, and demographics such as age, years of schooling and marital status. This is useful as administrative factory records often don't record worker age and almost never record any of the other measures available in the survey. A subset of 1,500 workers in the surveys, from 45 out of the 70 factories, also contain information on children of the respondents.

The survey samples contain operators on grades 6 through 3 selected randomly from given production lines. Workers of the lowest grade (7) are not included because they were not part of the original studies for which the data was collected. The production lines from which the operators are sampled were selected by the factory to participate in these studies and so are not random. However, we see few significant differences in the administrative variables between the subsample of workers for whom we have survey data and the much larger sample of workers not surveyed, so we believe they can be viewed as a random sample of factory workers from grades 6 through 3.

\section{Summary Statistics}

Table 1 provides summary statistics for our data. Panel 1 provides the factory level statistics that were discussed above. Panel 2 shows summary statistics on the worker level from the HR records, using the sample of workers present in the first month of 
data available from each factory. Workers have spent on average two years in the current factory, and their monthly base pay, not including overtime pay, bonuses, or deductions for absenteeism, is 6,000 BDT, a bit less than US\$ 70.13 About one-third (34 percent) of the workers that we observe in the first month of data exits the factory before the last observed month, while 8.2 percent received an internal promotion to a higher grade.

Panel 3 of Table 1 shows equivalent summary statistics on the worker level from the surveyed workers of grades 6 through 3. The surveyed workers are 73.8 percent female (the equivalent share in the HR data for workers in grades 6 through 3 is 74.5 percent). Their average age is 25.2 years, 78 percent are married, and 66 percent report having at least one child. They report having worked on average 3 years in the current factory, 6.3 years in the sector, and at 1.7 other garment factories prior to the current factory.

\section{Gender Wage Gaps}

We follow the empirical approach that is standard in the literature on gender wage gaps, running a regression of the form:

$$
\text { LnWage }_{\text {ifm }}=\alpha \text { Female }_{i}+\delta_{m}+\delta_{f}+\epsilon_{\text {ifm }}
$$

where Female is a dummy variable indicating that worker $i$ is female. We include fixed effects for month $m$ and factory $f$ and cluster standard errors at the factory level. We use the data for all workers recorded as working during the first month we have data from each factory. Results, however, are qualitatively unchanged throughout if we use the data from all months or for all 140,000 workers who are present in any month.

We start in Table 2 with the restricted set of 36 factories for which we have wage data for all sewing section workers, including supervisors. The grade 2 supervisor workers are 93 percent male and constitute 4.1 percent of all sewing workers on grades 2 through 7 in these 36 factories. Column 1 reports a basic regression with only factory and month fixed effects. We find that female workers earn about 20 log points less than male workers. On the right half of the table, in column 5, we repeat the same regression among the sample of workers in grades 3 through 7 using data from all 70 factories. Removing the (mostly male) supervisors leads to a drop of the wage gap to around 8 log

\footnotetext{
13 Throughout the period, the exchange rate was around 80 BDT per USD. The actual paid wage, including overtime pay, bonuses and deductions is 7,607 BDT, or about US\$ 95, for this sample, or almost $30 \%$ more than the base pay. However, in the reminder of the paper, we focus on the contractual monthly base pay of the worker, for 8 hours per day, 6 days per week.
} 
points. The smaller gap is not due to the factories in the expanded sample of 70 being different than those in the sample used in column 1; even in the sub-sample of 36 factories where we have grade 2 workers in the data set, the wage gap is 7.7 log points when the sample is limited to non-supervisory workers (column 4). The 8 percent earnings gap among our production workers is very similar to the 8.4 percent wage gap conditioned on industry and occupation that Blau and Khan report for the US (Blau and Khan, 2017).

In columns 2 and 6 of Table 2 we add grade fixed effects to the regressions using the restricted sample (column 2) and the full sample (column 6). Given the highly structured minimum wage laws governing the sector in Bangladesh, we should expect to find that controlling for worker grade will reduce the wage gap significantly. Indeed, we find the gap drops to only 1.2 percent in the sample of 36 factories (column 2) and 1.5 percent in the larger sample (column 6). These within-grade differences are not affected by interacting the factory and grade fixed effects. Thus, the wage gap is substantially a "grade gap". Men work on higher grades, but conditional on the grade, the wage gap is small (even though it remains statistically significant). Columns 3 and 7 confirm this by estimating the "grade gap" directly. We regress the ordinal grade level of each worker - reversed, so that a positive coefficient reflects a higher grade level against a dummy indicating the worker is female plus factory and month fixed effects. Using the restricted set of factories that includes supervisory workers, we find that the grade of women is, on average, 1.18 levels lower (column 3); limiting the sample to grades 7 through 3 and using the full set of 70 factories, the gap is slightly smaller, 0.79 levels (column 7). The economically and statistically significant grade gap, combined with the low wage gap conditional on worker grade leads us to frame the discussion in the reminder of the paper on the mechanisms that drive the grade gap.

\section{Controlling for Absenteeism and Overtime}

Men may earn more because they are perceived to be more reliable or more flexible in working hours. The administrative data for 34 of the 70 factories in the sample contain data on both worker absenteeism and overtime hours. Appendix Table A.1.a shows that women are on average absent on 50 percent fewer days per month and are 
more likely to receive an attendance bonus at the end of the month. ${ }^{14}$ However, women also work 4.5 percent fewer overtime hours than men. Women thus seem to be more reliable workers, albeit maybe less available for certain overtime needs of factories, resembling situations also observed in high-income country settings (Goldin 2014). In Appendix Table A.1.b we show that controlling for the average absenteeism or overtime hours of workers leaves the estimated wage and grade gaps unchanged, suggesting that neither absenteeism nor overtime hours explain any part of the gender gaps shown in Table 2.15

\section{Controlling for Worker Skills}

We have worker skills data for sewing operators (Grade 3 through 6) from 16 of the 70 factories for which we have HR data. Written promotion policies available from several factories indicate that skills captured by one or more of these measures is the most often mentioned criterion for promotion. In the few factories that assign weights to the criteria, these skills account for half or more of the weight. The promotion policies also routinely mention factory tenure and attendance. As we discussed above, Appendix Table A.1.b shows that attendance and overtime hours have no effect on worker grade.

In Column 1 of Table 3 we replicate the basic grade gap regressions of column 7 , Table 2 for operators from these 16 factories. This shows a grade gap of 0.371 for this sample. ${ }^{16}$ In column 2 , we verify that the four skills measures predict the grade of the worker. The results show that each of the four skills measures is significantly associated with higher grades. A one standard deviation increase in average efficiency corresponds to an increase of 0.15 grades. The effect is somewhat larger for number of different processes a worker can do (0.20), but the same as for the complexity of the most complex process she masters (0.15), and being able to do at least one process requiring physical strength (0.15). The skill measures therefore seem to capture meaningful variation in worker ability.

\footnotetext{
14 Attendance bonuses are typically small bonuses of not more of 10 percent of the monthly base wage, paid each month the worker was not absent more than 0,1 , or 2 days, depending on the factory.

15 It also does not affect the estimated wage gap conditional on grade fixed effects.

16 The drop from 0.79 grades shown in column 6 of Table 2 is entirely due to dropping grade 7 workers from the sample. The coefficient for grade 6 through 3 workers from the full sample of 70 factories is 0.376. As the data in Table 1 show, women are particularly over-represented on grade 7 positions.
} 
We next ask how much of the gender gap is accounted for by differences in skills. We add gender to the regression including the measures of skills in column 3. A comparison on columns 1 and 3 shows that adding the skills measures reduces the estimated grade gap by a third, to 0.25 grades. This drop increases to around 40 percent when also adding a set of indicator variables for the types of machines the worker is skilled on (column 4). The drop in the gender gap in column 3 suggests that females are less skilled in at least some dimensions. We examine this in columns 5 to 8 . We find that male workers are reported to be able to perform significantly more complex tasks, and tasks that require physical strength.

Replicating the results from columns 1-4 using log wage instead of grade as the dependent variable yields qualitatively similar results (available on request). However, the grade hierarchy provides a more homogeneous measure across factories of the career progression of workers, and so we focus in the next sections on understanding in more detail the evolution of the grade gap over the average career of men and women in the sector.

Collectively, the results on Table 3 show that up to half of the gender gap is explained by the lower skill acquisition of women, but the larger share comes from lower grades or wages conditional on the level of skills. We turn next to an exploration of why women are on lower grades even after we condition on skills.

\section{Grade Gap Decompositions}

Almost all workers in the sector start their career at grade 7.17 Thus, a worker's current grade indicates the number of promotions $\mathrm{s} /$ he has received to reach that grade. ${ }^{18}$ This allows us to decompose the gender grade gap along two dimensions. First, we can decompose the gap into the part coming from differences in average time spent in the sector and the part coming from differences in the rate of promotion for women and men. Second, workers may be promoted within a factory, or may receive a promotion when moving from one factory to another. We refer to promotions in the factory as internal, and promotions when moving across factories as external. Any differential promotion frequency between male and female workers can be decomposed into differences in internal and external promotion frequencies.

\footnotetext{
17 of all workers in the survey, 91 percent report to have started their career on grade 7.

${ }^{18}$ We occasionally observe workers in the HR data rising more than one grade in a single promotion. We treat these as multiple promotions occurring at the same time to the same person.
} 
The administrative data report factory tenure but not sector tenure. We know sector tenure only for the subset of workers who were surveyed. To estimate the portion of the grade gap coming from differences in the average sector tenure by gender, we run the grade gap regression on the survey sample and add a control for sector tenure. Table 4, column 1 shows that the basic gender grade gap among the surveyed workers is 0.375 grades, almost exactly the grade gap among grade 6 to 3 workers in the overall HR data. Column 2 of Table 4 adds years in sector as reported by the surveyed workers, and its square. The inclusion of these variables reduces the estimated grade gap to 0.25 , or by around 33 percent. Adding additional controls for education reduces the grade gap only marginally (column 3, Table 4).

Note that the survey samples for our factories do not include grade 7 workers. This is unfortunate because a large share of the grade / wage gap is accounted for by differential promotion rates from grade 7 . We address this by randomly sampling from the HR data a number of male and female grade 7 workers so that when these grade 7 workers are added to the sample of surveyed grade 6 to 3 workers, the share of grade 7 workers in that combined sample matches their share in the HR data. We then initially assume that sector tenure and factory tenure is the same for grade 7 workers - that is, that workers do not make lateral transfers without promotions on grade 7 . Column 4 of Table 4 shows a grade gap of 0.815 in the combined sample of grade 7 to 3 workers without controlling for sector tenure, close to the grade gap of 0.79 estimated from the full HR data in column 7, Table 2. Column 5 shows that adding estimated sector tenure explains about 50 percent of the overall grade gap of 0.81 we found in column 4 .

The assumption that workers never make lateral moves across factories on grade 7 is clearly not correct. To account for these lateral movements and estimate sector tenure for grade 7 workers more accurately, we use information from a survey sample of 190 grade 7 workers from four other factories not included in the administrative data used here. Using a non-parametric simulation technique explained in more detail in Appendix 2, we simulate sector tenures for the grade 7 workers added to the sample of surveyed workers of grade 6 to 3, based on the empirical joint distribution of factory and sector tenure among the 190 surveyed grade 7 workers. Different variations of this simulation approach consistently lead to sector tenure explaining somewhat less of the grade gap, compared to when using simply factory tenure as proxy for sector tenure among grade 7 workers. But the differences to when using simulated sector tenure are 
small (column 6, Table 4). We therefore consider using factory tenure as proxy for sector tenure for grade 7 workers as providing an upper bound for the share of the grade gap explained by differential sector tenure of men and women.

The skills data and differences in sector tenure appear to explain around 40 and 50 percent of the grade gap, respectively. Does that imply that together they explain 90 percent of the gap? The answer to the question is almost surely "no", because skills accumulate with experience. The skills gap and the tenure gap are surely two ways of measuring related factors, unless men accumulate skills significantly more quickly than women. Unfortunately, we have both skills and survey data only for a very small sample of 150 workers in nine factories. Nevertheless, Appendix C shows that in this small sample, there is a positive correlation of years in sector and at least two of the skills measures (Table C.1, column 4). Adding controls for skills to a grade-gap regression that controls for sector experience reduces the grade gap by an additional 25 percent (Table C.1, comparing columns 3 and 5), suggesting that the two together explain around 60 percent of the gap among sewing machine operators, though the remaining wage gap is not statistically significant anymore in the small sample of only 150 workers.

\section{Internal vs External Promotions}

Even if more than half of the wage gap is explained by gender differences in sector tenure and skills, these differences themselves may reflect disadvantages women experience in the sector. For example, if women are promoted less frequently than men, they may leave the sector earlier. Furthermore, promotion to higher grades may enable men to subsequently attain higher skills. For these reasons, understanding not only the gender wage gap in levels, but also how it evolves over worker careers, is of central interest. That is, do men raise up the ranks faster, do they so primarily within factories or by moving more often between factories, and are any differences explained by worker observables?

We observe internal promotion frequencies directly in our HR data, and we begin by presenting the evidence on internal promotion frequencies directly from these data. We do not observe external promotions in our data, as our data do not trace workers across factories. ${ }^{19}$ However, we show that we can recover external promotion rates by

\footnotetext{
${ }^{19}$ Even if a worker would move between two factories in our sample, the factories would assign factory specific identifiers to the worker. It is impossible to identify the same worker at different factories based
} 
combining data on the number of workers on each grade from the HR data with information on the average time the workers on different grades have spent in the sector, obtained from our survey data. This requires us to make additional assumptions on the data generating process. We make these assumptions clear by writing down a model that includes overall promotion rates as parameters, and whose parameter values can be obtained by fitting the model to the available data. This allows us to obtain external promotion rates for male and female workers by subtracting the observed internal promotion rates from the fitted overall promotion rates.

Table 5 shows the monthly internal promotion rates, overall and by grade, for male workers, and the difference in the rates of female workers. Promotion frequencies decline as workers climb the grade hierarchy. Internal promotion rates out of the lowest two grades (7 and 6) are around 2 percent per month for men (column 1), falling to $1.25 \%$ at grade 5 and to less than 1 percent per month for the more skilled grades. Internal promotion rates are 35 percent (grade 7) to 10 percent lower for women. This difference becomes larger and more statistically significant when controlling for factory fixed effects, suggesting that female workers select into factories that promote internally at higher rates, though the effect is not statistically significant at conventional levels. Furthermore, note that the lower promotion rates for women also depend on conditioning on worker grade. Overall, at any point in time the share of female and male workers in the sector being promoted is the same. However, this reflects the fact that women make up a larger share of workers on lower grades (Table 1), where promotion rates are higher.

The internal promotion rates appear low compared with rates implied by the grades of surveyed workers and their responses on years spent in the sector. For example, simply dividing the number of promotions implied by a surveyed worker's current grade by the reported years in the sector indicates for both men and women average annual promotion frequencies are around 0.5 , or 4 percent per month. Even the highest internal promotion rate, for men on grade 7 , is barely half that rate, while the overall promotion rates across all grades is just a quarter of that rate. However, the comparison of internal promotion rates from the HR data and average promotion rates from the survey data is not valid because it fails to account for selection of workers exiting the

on name only, and the administrative data does not provide much more identifying information than names. 
sector. If, for workers of different types, sector exit is differently correlated with past promotions, the difference between internal promotion rates from the HR data and those implied by the survey data cannot simply be assigned to external promotions. To clarify the nature of the problem, consider an extreme example. Suppose all workers start their career on grade 7. At the end of each period of time, a share $s$ of workers on any grade is promoted to the next grade, while the remaining share (1-s) leaves the sector. A survey of a cross-section of workers conducted at any point in time would capture only surviving workers, and show an average promotion rate of 1 rather than $s$. Estimating external promotion rates by simply differencing the overall promotion rate from the survey and the internal promotion rates from the HR records would then overstate the external promotion rates. This approach to back out external promotion rates would only be valid if the probabilities of exit from the sector and promotion are independent of one another. This seems very unlikely to be the case because we would expect promoted workers to be less likely to exit the sector. Thus, we need to estimate external promotion rates explicitly taking into account potentially different sector exit rates of men and women, and their correlation with promotions. We will return to this point later.

Averaging over the absolute gender differences in promotion rates across grades (without factory fixed effects), weighted by the number of female workers on each grade, yields a difference in promotion rates of 0.0040 promotions per month. This implies that men gain 0.048 grades (0.004 times 12 ) more per year than women from higher internal promotion rates. Given that female workers on grades 7 through 3 have spent an estimated 4.77 years on average in the sector, this translates into an "accumulated internal promotion advantage" for men of roughly 0.23 grades $(0.048$ times 4.77), before taking into account their longer average career length in the sector. ${ }^{20}$ Note, however, that this is a linear approximation of a promotion process that is inherently non-linear (concave) over worker careers, as shown in Table 5 by the decreasing promotion rates as workers progress to higher grades.

\footnotetext{
20 The 4.77 year average sector tenure is estimated using the survey data for sector tenure of workers in grades 6 through 3 ( 6 years) and the average factory tenure of grade 7 workers in the HR data, times 1.25 (1.75 years). The HR records indicate that grade 7 workers are 29 percent of all female workers. Hence $(6.0 \times 0.71)+(1.75 \times 0.29)=4.7$. See Appendix D for further details on estimating average sector tenure for workers on grade 7 .
} 
The concavity in promotions rates also invalidates simple comparisons of the grade and promotion rate gaps from the HR data. We cannot simply assign to external promotions the difference between the grade gap from the HR data- around 0.4 once adjusted for the different sector tenures of male and female workers - and the "accumulated internal promotion gap" of 0.23 . There may be no differences in average promotion rates over the careers of men and women but still a grade gap in crosssectional HR data, if, for example, the promotions of men occur earlier on in their careers $^{21}$. Thus, arguing that any wage or grade gap that is not explained by differences in average internal promotion rates (and career lengths) between men and women must be due to different external wage growth is not valid. To measure the relative frequency of internal and external promotions, we need an approach that takes both sector exit rates and the non-linearity of promotions over worker careers into account.

This leads us to write a model that explicitly incorporates sector exit rates, promotion rates, and the non-linearity of promotions over worker careers. We then fit the model to empirical moments we observe in the HR and the survey data, allowing us to back out estimates of (otherwise unobserved) sector exit rates and overall promotion rates, on each grade, separately for females and males. We can then obtain external promotion rates by simply subtracting at each grade the internal promotion rates, as obtained from the HR data, from the estimated overall promotion rates. Appendix D describes the model in detail. We summarize here the basic building blocks and discuss the estimates obtained for external promotion rates for male and female workers.

The model assumes that workers are of five types, indexed by the highest of the grades 7 through 3 that they will reach during their career. Each of the five worker types is characterized by three parameters; the rate of promotion through the lower grades to reach their final grade, the rate with which they exit the sector once they have reached their final grade, and the number of workers of that type that enter the sector at each period of time. The number of parameters can be reduced by two by setting the

\footnotetext{
${ }^{21}$ To see more formally how non-linearity of promotions over workers careers affects this comparison, consider another stylised model, in which there are only two grades, 0 and 1 . Each worker starts her/his career on grade 0 and exits the sector after $T$ periods of time. Consider that workers are of different types. Workers of type $h$ get promoted from grade 0 to grade 1 after $t_{h}<T$ periods of time. If new cohorts of workers of constant size for each type enter the sector each period in time, the average grade of all workers of type $h$ at any point in time would be $\left(T-t_{h}\right) / T$. Thus, if $t_{h}$ differs across worker types, a grade gap would be estimated between these workers. But average promotion rates would not differ across worker types. Thus, a comparison of grade gaps and (internal) promotion rates is only valid once the timing (or degree of non-linearity) of promotions is taken into account.
} 
number of workers entering the sector of one type as the numeraire, and because workers of type 7 are never promoted out of grade 7 and thus do not have a promotion rate. Thus, the model has 13 parameters whose values are unknown to us, and predicts values for 13 moments that we can observe in our HR and survey data: the four relative sizes of adjacent grades between grade 7 and 3, the five average sector tenures for workers currently working on grades 7 through 3, and the variance of sector tenure of workers currently on each grade 6 through $3 .^{22}$ Thus, we have an exactly identified model. There exists a unique value for each of the 13 unknown parameters so that the predicted moments from the model match those from the data. The model explicitly allows workers that will reach different highest grades during their career to be promoted and to exit the sector at different rates. Furthermore, by allowing the rate at which workers exit the sector once on their final grade to differ from the rate at which they got promoted before reaching that grade, we can model arbitrary levels of concavity of promotions over worker career, independently for each worker type. We fit the model separately for male and female workers.

To obtain predictions for the variance of sector tenure of workers on a certain grade, an additional modeling assumption has to be made on the pattern with which workers of a certain type on a certain grade are promoted or exit the sector, conditional on the rate with which they do so. For example, if $p$ workers of a certain type are promoted each period and $s$ exit the sector, then these workers could be those with the longest tenure on the grade among the respective type of workers. Alternatively, they could be selected independently of the time they already spent on that grade, or be selected in a way such that those that exit, or are promoted, have a uniform distribution over the time that they have already spent on the grade. In a cross section of workers of a certain type on a certain grade in the steady state, the first modeling option would result in a uniform distribution of time these workers have spent on their current grade, the second option in an exponential distribution, and the third in a triangular distribution. We discuss these modeling options in more detail in Appendix D.

It turns out that the model can be fitted for both women and men under the "uniform" assumption for both promotion and exit, and for women (only) under the uniform assumption for promotion and the "triangular" assumption for exit. Under the

\footnotetext{
22 Data constraints allow us to estimate average sector tenure for workers on grade 7, but not the variance of sector tenure among these workers. See more details on Appendix D.
} 
"exponential" assumption for either promotion or exit, it cannot be fitted for neither sex. ${ }^{23}$ We show in Table D.1 in Appendix D the parameter values and promotion rates on each grade we obtain when fitting the model under the only feasible set of assumptions for men, and the two feasible sets for women. We note that when fitting the model for women under the uniform assumption for both promotion and exit, some of the obtained parameter values are unrealistically large, while these values look much more realistic for women when using the "triangular" specification for exit. Thus the parameter values we obtain for men under the uniform assumptions for both promotion and exit, and for women under the uniform promotion / triangular exit assumptions are our preferred specification. We show the resulting external promotion rates from these particular specifications for each grade in Table 5, alongside the internal promotion rates from the HR data we discussed above. Note that the estimates we obtain for overall and external promotion rates are qualitatively similar for one important outcome when we use the uniform assumption for both promotion and exit for women. Specifically, for each grade, external promotion rates are higher for men than for women. Nevertheless, there are valid reasons to assume that the triangular specification for sector exit is more realistic for women than for men. For example, women may exit the sector for a more diverse set of reasons than men, such as childbirth, care for other family members, or other household-related reasons, many of which may arise in a less predictable manner over time. This should result in more variation in the time that women spend in the sector, a feature that would be captured by the triangular specification as opposed to the uniform one.

The results from the model indicate that, grade by grade, external promotion rates for both men and women are about the same or slightly higher than internal rates on grades 7 to 5 , while on grade 4 , all promotions to grade 3 are internal. ${ }^{24}$ However, given that internal promotion rates are 50 percent (grade 7) to 30 percent (grades 6 and 5) higher for men, external rates are also higher for men. The most pronounced difference is on the entry grade 7. Just under 5 percent (4.9) of men on grade 7 move out of the grade any given month, while only 2.9 percent of women do so, with the share of those doing so via external promotions being slightly higher for men.

\footnotetext{
${ }^{23}$ By "cannot be fitted" we mean that the set of parameter values that sets the predicted moments equal to those observed in the data contains infeasible values for some parameters, such as for example negative promotion or sector exit rates.

${ }^{24}$ We did not model promotions on grade 3 to grades beyond as at least for women they are negligible.
} 
Weighting the grade-specific external promotion gaps by the number of female workers in each grade, we estimate an external promotion rate gap of 0.0045 per month, or an annualized external promotion gap of 0.054 , slightly larger than the equivalent weighted gap for internal promotions of 0.048 . Jointly, the two gaps yield an estimated total promotion gap of 0.102 per year. Multiplied by 4.77, the estimated average tenure for women in the sector, the combined accumulated grade gap is then 0.49. This gap is just slightly larger than the gap of around $0.40-0.45$ grades from the HR data when adjusted for the longer tenure of men in the sector (from Table 4). Any remaining difference likely reflects factors like endogenous male and female sector exit rates and non-linearities in promotion, which we ignore for simplicity in this linearized calculation. The model indicates, however, that the (accumulated) external promotion gap is slightly larger than the (accumulated) internal promotion gap, which is mainly driven by promotions out of the early grades in worker careers.

We conclude this section with a brief discussion of how selection out of the observed workforce affects the estimated gender gap. We have already shown that there is no pronounced selection from the general population into the sewing workforce, at least along the crucial dimension of education. However, selection into the labor force is only one part of the concern. If lower-ability workers leave the sector faster (slower), average pay would increase faster (slower) with tenure in a cross-section of workers. And if the relationship between ability and sector exit differs for women and men, the differential exit would affect the estimated wage gap. A simple test for selection is to compare worker observables for workers on the highest grade 3 with the average worker, and to see if that pattern differs between men and women. Table 6 shows such a tests on education, being married and having children. Generally, we do not find strong effects, though for education, the point estimate of the difference between grade 3 workers and all workers in the surveys is positive for men while negative for women, with the difference significant at the 10 percent level. This indicates that men who remain in the sector are more selected in education than women (column 1, Table 6). We also find that women on the highest grade are marginally significantly less likely to be married than the average woman in the sector, suggesting that getting married induces some women to leave the sector before reaching the highest grade. But the difference to the effect for men is not significant. We do not find evidence for selection 
on children, or that any of the selection process has changed over the time covered in our sample, when interacting the gender indicator variables with time trends.

The parameters of the model we fitted to the data include a distribution of the share of workers entering the sector in the steady state with respect to the highest grade they will reach during their career. This allows us to quantify the overall effect of selection out of the sector on the wage gap. We can create a counterfactual wage gap by assuming that workers of the different types spend the same time in the sector, and that a worker on a given grade earns the average wage from our HR data for workers on that grade. Using the data from our preferred specification, we would obtain a wage gap of 8.09 percent, which is almost exactly as the estimated gap from Table 2. Thus, selection of the sector does not seem to affect the estimated wage gap much. This may not be surprising given that our estimated type distributions across workers as they enter the sector, as shown in Table D.1, track the empirical distribution of workers across grades in the HR data very closely, for both men and women (Table 1, Panel 2). It is also consistent with the evidence that on observables we find only weak evidence on differential selection out of the sector between male and female workers.

\section{Drivers of Grade and Promotion Gaps}

Having determined the relative importance of internal and external promotions for career advancement of women and men in the sector, we next turn to examining the extent to which observable worker skills and characteristics are associated with internal and external promotion rates. Table 3 shows that our four skill measures are highly correlated with worker grade. In Table 7, we ask whether skills also explain gender gaps in promotion rates in our data. Are men more likely to be promoted because they are accumulating skills more quickly on a given grade? In columns 1 through 4 of Table 7 , we replicate the basic skill-gap regressions from columns 5 through 8 of Table 3, but conditioning on grade fixed effects. The results are very similar to those on Table 3. Men have higher skill levels on complex tasks and those that require physical strength. In column 5 we show that the gender gap in internal promotion rates is around 15 percent per year. ${ }^{25}$ In column 6, we test the relationship between skills and promotions by regressing promotions on the four skill measures and grade fixed

\footnotetext{
${ }^{25}$ In this section, all monthly promotion variables are multiplied by twelve to make coefficients interpretable as (differences in) annual rates.
} 
effects. Task complexity is the only skill that predicts promotions. Adding the female worker dummy (column 7) shows that, relative to column 5, controlling for skills reduces by half the gender gap in promotion rates. Adding the set of machine-type controls (column 8) reduces the remaining gap slightly further to 7.2 percent and leaves the coefficient on female workers marginally insignificant (p-value 0.113 when clustered at factory level). While there are gender differences in skills even within worker grade, the gender gap in internal promotion rates seems not fully explained by skill levels.

This leads us to the second of the three main drivers of the gender gap, differential constraints on men and women arising from obligations outside of the workplace. Specifically, we follow the long line of literature that has argued that gender-specific household roles are important drivers of gender gaps in labor market outcomes. We do this in Table 8, first examining the extent to which marriage can explain the grade gap directly by comparing married and unmarried workers. Around 70 percent of male workers and 80 percent of female workers in our sample report being married. We expect to find that married women face higher mobility frictions than single women, as they spend more time and effort on household duties. Column 1 of Table 8 simply repeats column 3 of Table 4, to make comparisons easier. We regress worker grade on a female worker dummy, controlling for tenure in the sector and the factory, average years per factory, age and education level. In column 2 we show that controlling for being married has no effect on the results. In column 3 we interact marriage with worker gender. This interaction reduces the wage gap by less than 10 percent while the variable indicating the worker is married remains insignificant for either gender.

Columns 4-6 and columns 7-9 of Table 8 repeat columns 1-3 using internal promotions and years spent per factory over a worker's career, respectively, as dependent variables. We use average tenure per factory over the worker's career as a proxy for otherwise unobserved external promotions for individual workers, as this captures the combined rate of external promotions and lateral movements between factories. ${ }^{26}$

\footnotetext{
26 The number of factories a worker has worked in over his or her career is a highly statistically significant predictor of his or her grade, even when clustering standard errors on the factory level. This suggests a strong predictive power of the rate with which a worker moves between factories for the worker's rate of external promotions. The relationship is marginally stronger for women ( $p$-value $=0.1$ ).
} 
In the sample of surveyed workers, women are 6 percentage points less likely to receive an internal promotion each year, conditional on grade and basic observables (column 4). This is reasonably close to the gender gap in promotion rates in the overall HR data, which is 4.8 percentage points controlling for factory and grade fixed effects. ${ }^{27}$ Women also move between factories at a 30\% slower pace than men, and hence spend an average of 0.7 more years per factory over their career (column 7). Controlling for being married does not affect these numbers (columns 5 and 8). However, allowing the effects of marriage to differ between males and females reduces the baseline gender gap in internal promotion rates by almost half, leaving it statistically insignificant (column 6). This effect is driven by married men receiving more promotions then unmarried men; married and unmarried women receive internal promotions with equal frequency. ${ }^{28}$ The pattern is similar for our proxy of external promotions, as shown in column 9. The gender gap in years spent per factory is almost twice as large between married men and women as it is between unmarried men and women. And again, we find that married men move more frequently than unmarried men, with the difference now statistically significant, while married and unmarried women move at roughly the same rate. The data show a consistent picture, pointing to marriage leading to changes in incentives for men rather than changing mobility for women. ${ }^{29}$ This result resembles those from an older literature from high-income settings that showed that being married boosts the careers for men (for recent summaries of that literature see de Linde Leonard and Stanley, 2015, and Sobel, 2012).

A further potentially important factor is whether workers have children. A growing literature using data from high-income countries shows that the gender wage gap is increasingly found to be a mother wage gap (Kleven et al. 2018, 2019). We explore the

\footnotetext{
27 The worker's grade is an outcome of her accumulated promotions, so grade is endogenous to promotions and may therefore be a "bad control". Running Columns 4-9, Table 6 without grade fixed effects does not change the results fundamentally. On the other hand, the distribution of female and male workers across grades differs significantly (as shown in Table 1), as does the promotion pattern across grades. Therefore, not including grade fixed effects potentially confounds the coefficient estimates by strong compositional effects. We therefore prefer to show results including grade fixed effects. The results should be interpreted as indicators of differential treatment of men and women, conditional on having made it to the same position.

${ }^{28}$ Note, however, that the effect on men (who are only around 20 percent of the sample) is not statistically significant.

${ }^{29}$ Note that these regressions control for education and age. In our sample, education and being married is negatively correlated for women. We therefore caution to interpret the results on marriage as strictly causal. Married and non-married women may differ on a number of characteristics, many of them unobservable.
} 
role of children in Table 9. However, our surveys included questions on children in only 45 of the factories, which contribute around 45 percent of all surveyed workers. Thus, Table 9 repeats Table 8 on the sample from these 45 factories. But instead of adding variables indicating marital status, we add an indicator variable for having any child, any child younger than five years in columns 2, 5 and 8, and interactions of these variables with being female in columns 3,6 , and 9 , respectively. ${ }^{30}$ None of the gaps on the three outcome variables grade, internal promotions, and years per factory, is affected in a meaningful way by adding these controls. ${ }^{31}$

Mobility may also lead to higher wages if workers move to firms paying, on average, higher wages. Their wage rate would go up even if they remain at the some point in the firm wage distribution. Recent literature from high-income settings has shown that around 20 percent of the static, and up to 40 percent of the dynamic wage gaps over the life cycle of female and male workers is due to stronger sorting of men to firms that pay on average more (Card et al. 2016, Barth et al. 2019, Goldin et al 2017). A simple test for the presence of this type of sorting is to compare the wage gaps when controlling for firm fixed effects or not. If the inclusion of firm fixed effects reduces the wage gap, it implies that men work on average at better paying firms. However, in our data, we find that adding firm fixed effects increases slightly (and insignificantly) the point estimate of the wage gap. Thus, if anything, women work on average at firms that pay on average slightly more. The pattern is constant when looking at the pay gap grade by grade. Thus, there is also no evidence that, as workers move from lower to better grades over their careers, men sort to better paying firms.

The data thus provide a consistent picture. Married men in particular move more often across factories than unmarried men, and even more often than women. Men are also more skilled than women, even conditioning on their current position (grade). They seem to have a particularly advantage in more complex sewing processes, and this

3077 percent of men and 73 percent of women report having at least one child, while 53 and 34 percent, respectively, report having a child younger than 5 years.

${ }^{31}$ Children might affect the grade gap indirectly, by inducing some women to exit the sector. Moreover, this exit could be differentially selected on ability. Given that we do not observe workers who have left the sector, this channel is difficult for us to quantify. However, we note that in our worker surveys, the proportion of female workers with children increases to 80 percent by age 25. This is close to the overall share of women with children at age 25 in Bangladesh, which is 90 percent (Labor Force Survey 2017). Furthermore, age 25 is the peak of the age distribution among women in the sector, implying that most women have children before exiting the sector. This suggests that women do not generally drop out of the sector with the birth of their first child. However, it may still be the case that part of the higher sector exit rates we estimate with the model are driven by childbirth. 
is the skill that seems to be most associated with internal promotions. On the other hand, we find relatively little evidence that household responsibilities, proxied by being married or having children, affect the mobility of women. It thus seems that men in the sector have stronger motivation to reach higher positions.

Why might this be so? Logically, it must be the case that either women's cost of investing in skills is higher or the expected returns to those skills are lower. We see two reasons why the returns to skills might be lower for women. First, there may be differences in returns to skills in operator positions. We examine this on Table 10 , where we regress wages on skills, allowing the effects of skills to differ for women and men. We find that women have significantly lower returns for one skill - the complexity of tasks. Notably, this is also the skill that appears to matter for (internal) promotions. Second, as discussed in Macchiavello et al. (2016), women have been largely excluded from higher-level positions in the sector. The lower potential for promotion into management positions may be a cause of shorter careers and also reduce the benefit of acquiring skills in operator positions. We read the collective results as showing that the gender wage / grade gaps are caused primarily by lower investment by women and lower returns conditional on investment rather than mobility frictions and bargaining.

\section{Conclusion}

We present, to the best of our knowledge, the first evidence on gender wage gaps in a developing country using administrative wage data. Our data come from a large number of factories representative of one of the more successful export sectors in the past couple of decades. Export manufacturing is viewed as one of the few development strategies that has been successful in generating sustained economic growth. However, there are also widespread criticisms of export manufacturers for not safeguarding labor (and environmental) standards. Given this, we consider this setting to be of particular policy interest. ${ }^{32}$ The size of the sector, its exploitation of the country's comparative advantage in cheap unskilled labor, and its employment of large numbers of female workers in a context where female labor force participation rates are otherwise low is representative of export sectors more generally in many developing countries.

\footnotetext{
32 Blattman and Dercon (2018) and Boudreau (2019) provide excellent summaries on the academic literature on labor standards in export manufacturing. For the broader debate on the role of export manufacturing in development, see also the literature summary on the ISID policy brief 2019-03 (ISID 2019).
} 
Our data are detailed at the level of the factory, but do not trace workers after they leave the factory. Thus, while we observe promotion rates within factories, we are not able to observe directly promotions that coincide with movement across factories or sector exit. However, we develop a framework that allows us to back out estimates of external promotion and sector exit rates for male and female workers, using survey data on average time spent in the sector and grade. Calibrating the model produces estimates of external promotion rates that are slightly larger than internal rates for men and women on lower grades, but are close to zero for promotion to the highest grade.

With regard to the gender wage gap, we view our results as providing a relatively clear and coherent picture. Within a very narrowly defined set of occupations, we find that men are paid on average around 8 percent more than women. With men and women starting on the same pay-grade as they enter the sector, roughly half of the wage gap owes to men staying longer in the sector, and therefore having more time to accumulate promotions. The rest owes to men being promoted faster, with the promotion differences coming roughly half from internal promotions and men reaping more promotions as they move between factories. Within a subset of the occupations where we have quite detailed skills data, we find that around two thirds of the gender gap is explained jointly by differences in skills and sector tenure. Somewhat surprisingly, we see little evidence that the lower rates of movement across factories is driven by women's marital status or child-bearing. While we can't rule out a role for higher mobility frictions for women, either because of household responsibilities or higher commuting costs, the data point to higher levels of ambition by men as the main cause of the wage gap in this specific context. 


\section{References}

Abras, A.L.G. 2012. "Success and upgrading after the end of the MFA." In G. LopezAcevedo and R. Robertson (eds): Sewing success? Employment, wages, and poverty following the end of the Multi-fibre Arrangement (Washington, DC, World Bank), 87135.

Albrecht, Jim, and Mary Ann Bronson, Peter Thoursie, and Susan Vroman. 2018. "The Career Dynamics of High-Skilled Women and Men: Evidence from Sweden." European Economic Review 105: 83-102

AT Kearney. 2014. "Get Ready for China's Manufacturing Comeback." atkearney.cz/documents

Azmat, Ghazala, and Rosa Ferrer. 2017. "Gender Gaps in Performance: Evidence from Young Lawyers." Journal of Political Economy 125 (5): 1306-1355

Babcock, Linda, and Sara Laschever. 2003. “Women Don't Ask: Negotiation and the Gender Divide." Princeton: Princeton University Press.

Barth, Erling, Sari Kerr, and Claudia Olivetti. 2019. "The Dynamics of Gender Wage Differentials: Evidence from Establishment Data." NBER WP 23381 (newer version from February 2019 available)

Belloni, Alexandre, Victor Chernozhukov, and Ying Wei. 2016. "Post-Selection Inference for Generalized Linear Models with Many Controls." Journal of Business \& Economic Statistics 34 (4): 606-619

Bertrand, Marianne, Claudia Goldin, and Lawrence F. Katz. 2010. "Dynamics of the Gender Gap for Young Professionals in the Financial and Corporate Sectors." American Economic Journal: Applied Economics 2 (3): 228-55,

Bertrand, Marianne, Emir Kamenica, and Jessica Pan. 2015. "Gender Identity and Relative Income within Households." Quarterly Journal of Economics 130 (2): 571614.

Black, Dan A. 1995. "Discrimination in an Equilibrium Search Model." Journal of Labor Economics 13(2): 309-333

Blattman, C., and S. Dercon. 2018. "The Impacts of Industrial and Entrepreneurial Work on Income and Health: Experimental Evidence from Ethiopia." American Economic Journal: Applied Economics 10 (3): 1-38.

Blau, Francine, and Lawrence Khan. 2017. "The Gender Wage Gap: Extent, Trends, and Explanations.” Journal of Economic Literature 55 (3): 789-865

Boring, Anne. 2017. "Gender biases in student evaluations of teaching." Journal of Public Economics 145: 27-41

Boudreau, Laura. 2019. "Multinational Enforcement of Labor Law: Experimental Evidence from Bangladesh's Apparel Sector.” Working Paper, UC Berkeley. 
Boudreau, Laura, Rachel Heath, and Tyler H. McCormick. 2019. "Migrants, Information, and Working Conditions in Bangladeshi Garment Factories." Working Paper, UC Berkeley

Bowles, Hannah R., Linda Babcock and Lei Lai. 2007. "Social Incentives for Sex Differences in the Propensity to Initiate Negotiation: Sometimes It Does Hurt to Ask." Organzational Behavior and Human Decision Processes 103 (1): 84-103.

Bronson, Mary Ann, and Peter S. Thoursie. 2019. "The Wage Growth and WithinFirm Mobility of Men and Women: New Evidence and Theory." Working Paper, Georgetown University.

Cameron, Colin, Jonah Gelbach, and Douglas Miller. 2008. "Bootstrap-Based Improvements for Inference with Clustered Errors." Review of Economics and Statistics 90: 414-427.

Card, David, Ana Rute Cardoso, and Patrick Kline. 2016. "Bargaining, Sorting, and the Gender Wage Gap: Quantifying the Impact of Firms on Relative Pay of Women." Quarterly Journal of Economics 131 (2): 633-686

Card, David, Stefano DellaVigna, Patricia Funk, and Nagore Iriberri. 2018. "Are Referees and Editors in Economics Gender Neutral?" Working Paper, UC Berkeley

Cook, Cody, Rebecca Diamond, Jonathan Hall John A. List, and Paul Oyer. 2018. "The Gender Earnings Gap in the Gig Economy: Evidence from over a Million Rideshare Drivers." Working Paper, Stanford University

Corcoran, Mary E., Paul Courant, and Mary C. Noonan. 2005. "Pay Differences among the Highly Trained: Cohort Differences in the Sex Gap in Lawyers' Earnings." Social Forces 84 (2): 853-72.

Croson, Rachel and Uri Gneezy. 2009. "Gender Differences in Preferences." Journal of Economic Literature 47 (2): 448-474.

de Linde Leonard, Megan, and Tom Stanley. 2015. "Married with Children: What Remains when Observable Biases are Removed from the Reported Male Marriage Wage Premium." Labor Economics 33: 72-80

Del Bono, Emilia, and Daniela Vuri. 2011. "Job Mobility and the Gender Wage Gap in Italy." Labour Economics 18: 130-142

Egan, Mark L, Gregor Matvos, and Amit Seru. 2017. "When Harry Fired Sally: The Double Standard in Punishing Misconduct." NBER Working Paper No. 23242

Flory, Jeffrey A., Andreas Leibbrandt and John A. List. 2015. “Do Competitive Work Places Deter Female Workers? A Large-Scale Natural Field Experiment on Gender Differences in Job-Entry Decisions." Review of Economic Studies 82(1): 122155.

Giuliano, Paola. 2017. “Gender: An Historical Perspective.” NBER Working Paper 23635

Goldin, Claudia, and Cecilia Rouse. 2000. "Orchestrating Impartiality: The Impact of "Blind" Auditions on Female Musicians." American Economic Review 90 (4): 715741. 
Goldin, Claudia. 2014. "A Grand Convergence: Its Last Chapter." American Economic Review 104 (4): 1091-1119.

Goldin, Claudia, Erling Barth, Sari Kerr, and Claudia Olivetti. 2017. "The Expanding Gender Earnings Gap: Evidence from the LEHD-2000 Census." American Economic Review P\&P 107 (5): 110-114

Groot, Wim, and Maartje Verberne. 1997. "Aging, Job Mobility, and Compensation." Oxford Economic Papers 49: 380-403

Haque, A.K. Enamel. 2015. "Garment Workers in Bangladesh: Social Impact of the Industry." Dhaka: Asian Center for Development

Hengel, Erin. 2018. "Publishing while Female." Working Paper, University of Liverpool

Hospido, Laura. 2009. "Gender Differences in Wage Growth and Job Mobility of Young Workers in Spain." Investigaciones Economicas 33(1): 5-37

Huynh, Phu. 2016. "Assessing the gender pay gap in Asia's garment sector." ILO Asia-Pacific working paper series.

Impactt. 2011. "Finding the Sweet Spot: Smarter ethical trade that delivers more for all." https://impacttlimited.squarespace.com

----. 2012. "Nice Work? Are workers taking the strain in the economic downturn? 2006-2012." https://impacttlimited.squarespace.com

----. 2013. “Nicer Work? Impactt's Benefits for Business and Workers Programme 2011-2013." https://impacttlimited.squarespace.com

ISID. 2019. "Working in Export Manufacturing: A Blessing or a Curse?", ISID Policy Brief PB-2019-03, by F. Amodio and A. Menzel

Jayachandran, Seema. 2015. "The Roots of Gender Inequality in Developing Countries." Annual Review of Economics 7: 63-88.

Kleven, Henrik, Camille Landais, and Jakob Egholt Sogaard. 2018. "Children and Gender Inequality: Evidence from Denmark." American Economic Journal: Applied Economics, forthcoming

Kleven, Henrik, Camille Landais, Johanna Posch, Andreas Steinhauer, and Josef Zweimuller. 2019. "Child Penalties across Countries: Evidence and Explanations." Working Paper, Princeton University

KPMG. 2013. "Business Case Analysis for Responsible Electronics Manufacturing" kpmg.com/TW/zh/Documents

Leibhardt, Andreas, and John A. List. 2014: "Do Women Avoid Salary Negotiations? Evidence from a Large-Scale Natural Field Experiment." Management Science 61(9): 2016-2024 
Loprest, Pamela. 1992. "Gender Differences in Wage Growth and Job Mobility." American Economic Review 82(2): 526-32

Macchiavello, Rocco, Andreas Menzel, and Christopher M. Woodruff. 2016. "Challenges of Change: An Experiment Training Women to Manage in the Bangladeshi Garment Sector.” Working Paper, CERGE-EI

Manning, Alan. 2013. "Monopsony in Motion: Imperfect Competition in Labor Markets." Princeton: Princeton University Press.

Mazei, Jens, Joachim Hüffmeier, Philipp Alexander Freund, Alice F. Stuhlmacher, Lena Bilke, and Guido Hertel. 2015. "A Meta-Analysis on Gender Differences in Negotiation Outcomes and Their Moderators." Psychological Bulletin 141 (1): 85-104.

MacNell, Lillian, Adam Driscoll, and Andrea Hunt. 2015. "What's in a Name: Exposing Gender Bias in Student Ratings of Teaching." Innovative Higher Education 40 (4): 291-303

Mengel, Frederike, Jan Sauermann, and Ulf Zölitz. 2018. "Gender Bias in Teaching Evaluations." Journal of the European Economic Association 17(2): 535-566

Sarsons, Heather. 2017. "Gender Differences in Recognition for Group Work." Working Paper, University of Toronto

Sarsons, Heather. 2019. "Interpreting Signals in the Labor Market: Evidence from Medical Referrals." Working Paper, University of Toronto

Sobel, Michael E. 2012. “Does Marriage Boost Men's Wages?: Identification of Treatment Effects from Fixed Effects Regression Models for Longitudinal Data." Journal of the American Statistical Association 107: 521-529.

Topel. Robert H., and Michael P. Ward. 1992. "Job Mobility and the Careers of Young Men." Quarterly Journal of Economics 107 (2): 439-479

WSJ. 2013. "Companies Seek to Avoid China New Year Hangover." wsj.com/articles/SB10001424127887323864304578315872427597756. 


\section{Education and Birth Cohort, Census and Surveyed Workers}

incl. 25th and 75th percentile

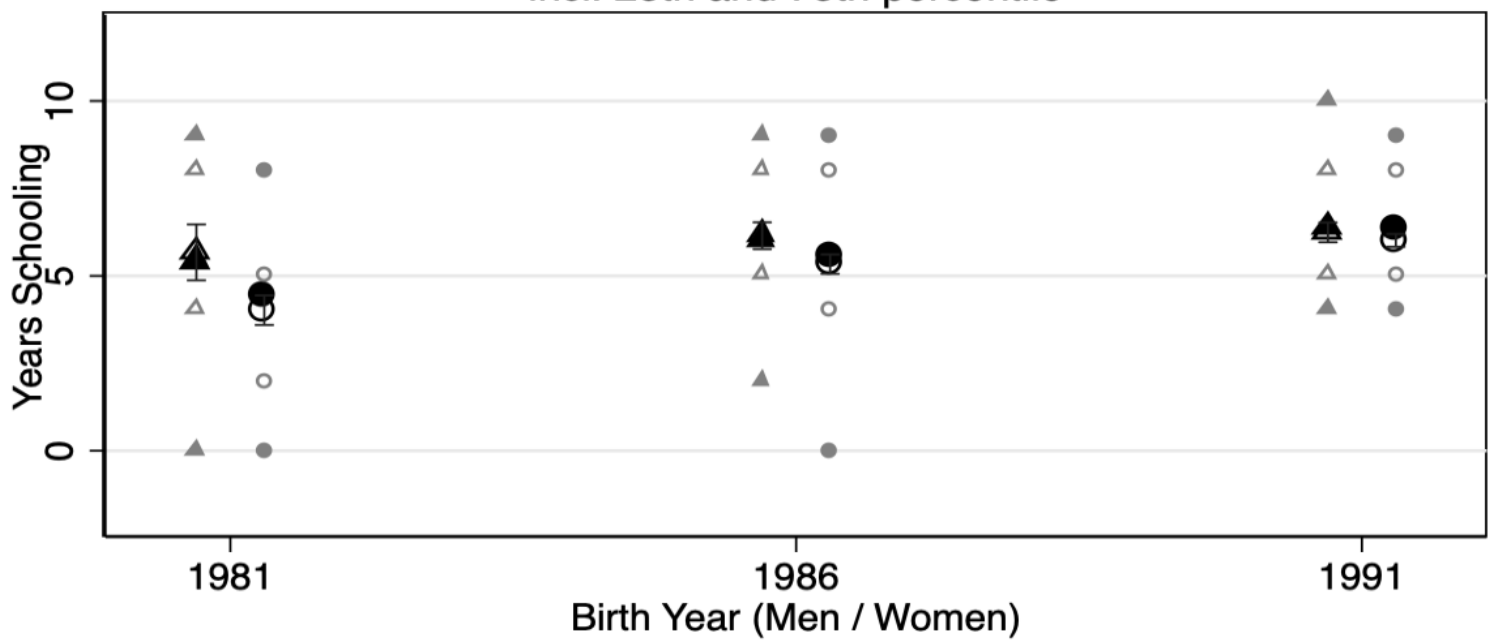

Birth Year (Men / Women)

$\begin{array}{ll}\Delta \text { Men, Census } & \text { Women, Census } \\ \Delta \text { Men, Census 25 \& 75 pc } & - \text { Women, Census 25 \& 75pc } \\ \Delta \text { Men, Worker } & \circ \text { Women, Worker } \\ \Delta \text { Men, Worker 25 \& 75pc } & \circ \text { Women, Worker 25 \& 75pc }\end{array}$

Figure 1: Selection into Garment Sector. Graph shows average years of schooling from the Bangladeshi census (solid symbols), and from our surveys of sewing workers of Grades 6-3 (hollow symbols), separately for workers born 1979-1983 ("1981"), 1984-1988 ("1986"), and 1989-1993 ("1991"). For both census and survey data, mean years of schooling, and $25^{\text {th }}$ and $75^{\text {th }}$ percentiles are shown. Data for men to the left (triangular symbols) and for women to the right (circle symbols). Mean years of schooling from surveys shown with $95 \%$ confidence intervals.

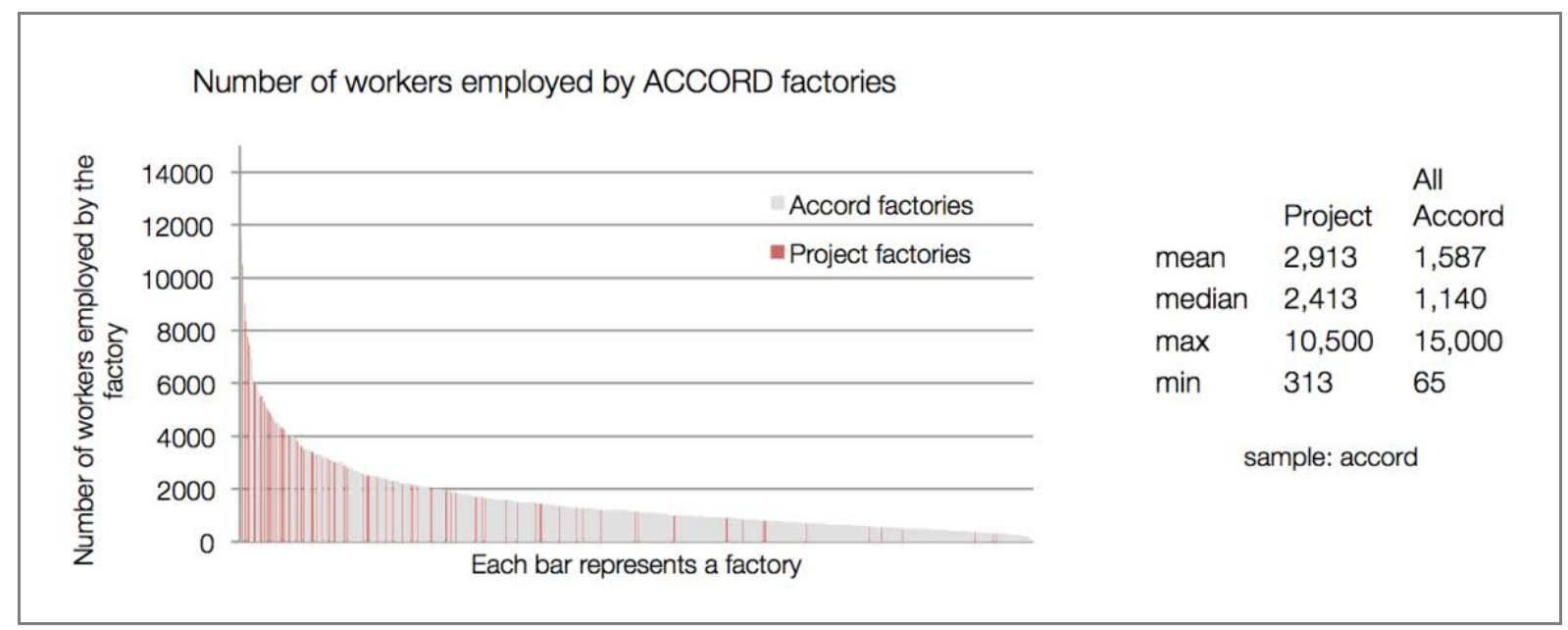

Figure 2: Project factories among the distribution of Alliance and Accord Factories. Graph shows the distribution of number of workers per factory among the ca. 2,000 factories organized in the buyer groups Alliance and Accord, with the factories participating in the project marked in red. 
Table 1: Summary Statistics

\begin{tabular}{|c|c|c|c|c|c|}
\hline Panel 1: Factory Level Statistics & & & & & \\
\hline Variable & $\mathrm{N}$ & median & mean & $\min$ & $\max$ \\
\hline Factory Size, Sewing Section & 70 & 1071 & 1294 & 133 & 441 \\
\hline Share Female Worker & 70 & 0.80 & 0.80 & 0.54 & 0.9 \\
\hline Tenure in Factory (years, HR data) & 66 & 2.14 & 2.26 & 0.89 & 6.3 \\
\hline Monthly Promotion rate (Not demoted) & 70 & 0.00 & 0.00 & 0.00 & 0.0 \\
\hline Monthly Exit rate & 70 & 0.05 & 0.05 & 0.00 & 0.1 \\
\hline \multicolumn{6}{|c|}{ Panel 2: Worker Level, HR Records, those present in first round of data } \\
\hline $\begin{array}{l}\text { Sewing Worker Sample, Grades } 7-3 \text {, with } \\
\text { non-missing gender, grade and pay: }\end{array}$ & $\mathrm{N}$ & median & mean & $\min$ & $\max$ \\
\hline Female & 81,5 & 1 & 0.79 & 0 & 1 \\
\hline Tenure in Factory (years, HR data) & 72,0 & 1.23 & 2.06 & 0 & 31. \\
\hline Base Wage (monthly, no overtime, BDT) ${ }^{33}$ & 81,5 & 6,15 & 5,94 & 752 & 14, \\
\hline Grade & 3 & 4 & 5 & 6 & 7 \\
\hline Male, Share & $26 \%$ & $34 \%$ & $15 \%$ & $13 \%$ & $12 \%$ \\
\hline Female, Share & $11 \%$ & $24 \%$ & $18 \%$ & $19 \%$ & $29 \%$ \\
\hline Male, Promoted internally within 12 months & NA & $3.8 \%$ & $14 \%$ & 17.5 & $16 \%$ \\
\hline Female, Promoted internally within 12 & NA & $2.0 \%$ & $8.1 \%$ & $7.6 \%$ & 8.6 \\
\hline Male, Left Factory within 12 months & $34 \%$ & $35 \%$ & $36 \%$ & $35 \%$ & $49 \%$ \\
\hline Female, Left Factory within 12 months & $32 \%$ & $34 \%$ & $35 \%$ & $36 \%$ & $42 \%$ \\
\hline \multicolumn{6}{|l|}{ Panel 3: Worker Survey Data } \\
\hline & $\mathrm{N}$ & median & mean & $\min$ & $\max$ \\
\hline Female & 2,40 & 1 & 0.73 & 0 & 1 \\
\hline Age & 2,40 & 25 & 25.1 & 16 & 35 \\
\hline Married & 2,40 & 1 & 0.77 & 0 & 1 \\
\hline At least one child & 1,36 & 1 & 0.65 & 0 & 1 \\
\hline Tenure in Factory (years) & 2,39 & 2.16 & 2.99 & 0 & 26 \\
\hline Tenure in Garment Sector (years) & 2,39 & 5.49 & 6.23 & 0.05 & 26 \\
\hline Nbr. of previous Factories & 2,39 & 1 & 1.73 & 0 & 19 \\
\hline
\end{tabular}

${ }^{33}$ At the time of data collection, US\$ $1 \cong 80$ BDT 
Table 2: General Gender Wage- and Grade Gaps

(1)

(2)

(3)

(4)

Grades 3-7

\begin{tabular}{lccc|cccc} 
Sample & \multicolumn{2}{c}{ Grades 2-7 } & \multicolumn{7}{c}{ Grades 3-7 } \\
Dep. Variable & Log Wage & Log Wage & Grade & Log Wage & Log Wage & Log Wage & Grade \\
\hline \hline & & & & & & & \\
Female Worker & $-0.206^{* * *}$ & $-0.012^{* * *}$ & $-1.184^{* * *}$ & $-0.077^{* * *}$ & $-0.080^{* * *}$ & $-0.015^{* * * *}$ & $-0.791^{* * *}$ \\
& $(0.017)$ & $(0.003)$ & $(0.078)$ & $(0.007)$ & $(0.007)$ & $(0.005)$ & $(0.062)$ \\
Observations & 46,134 & 46,134 & 46,201 & 44,267 & 81,508 & 81,508 & 81,581 \\
Nbr. Factories & 36 & 36 & 36 & 36 & 70 & 70 & 70 \\
& & & & & & & YES \\
Factory \& Month FE & YES & YES & YES & YES & YES & YES & YES \\
Grade FE & NO & YES & - & NO & NO & YES & - \\
\hline
\end{tabular}

Notes: Table shows the results from regressing log monthly basic wage (excluding overtime and bonus payments, and deductions from missing days), and inverted grade ( 7 - grade) on an indicator variable that workers is female, and on factory and months fixed effects. Columns 2 and 6 also control for worker grade fixed effects. Unit observations is worker-month. Data from first month of data available from factory. Columns 1-3 based on sample of all workers in factory's sewing sections of grades 2 to 7 , from the 36 factories from which consistent data on supervisor workers of grade 2 is available in HR data. Columns 4-7 based on sample of all workers in factory's sewing sections of grade 3-7, from all 70 factories in dataset. Standard Errors clustered at Factory level. Asterisks indicate significance at the $.10(*), .05(* *)$, and $.01(* * *)$ levels.

Table 3: Grade Gaps with Worker Skill Data

\begin{tabular}{|c|c|c|c|c|c|c|c|c|}
\hline & (1) & $(2)$ & (3) & (4) & (5) & (6) & $(7)$ & (8) \\
\hline Dep. Variables & Grade & & & & $\begin{array}{l}\text { Avg. } \\
\text { Efficiency }\end{array}$ & $\begin{array}{l}\text { Nbr. } \\
\text { Skills }\end{array}$ & $\begin{array}{l}\text { Highest } \\
\text { Complex. }\end{array}$ & $\begin{array}{c}\text { Phys. } \\
\text { Strength }\end{array}$ \\
\hline Female Worker & $\begin{array}{c}-0.371^{* * * *} \\
(0.070)\end{array}$ & & $\begin{array}{c}-0.252^{* * * *} \\
(0.070)\end{array}$ & $\begin{array}{c}-0.220^{* * *} \\
(0.075)\end{array}$ & $\begin{array}{c}0.000 \\
(0.071)\end{array}$ & $\begin{array}{l}-0.063 \\
(0.064)\end{array}$ & $\begin{array}{c}-0.403^{* * * *} \\
(0.043)\end{array}$ & $\begin{array}{c}-0.309^{* * * * *} \\
(0.038)\end{array}$ \\
\hline Average Efficiency & & $\begin{array}{c}0.115^{* * * *} \\
(0.035)\end{array}$ & $\begin{array}{c}0.114^{* * * *} \\
(0.035)\end{array}$ & $\begin{array}{c}0.107^{* * * *} \\
(0.032)\end{array}$ & & & & \\
\hline Nbr. Skills & & $\begin{array}{c}0.201^{* * * *} \\
(0.011)\end{array}$ & $\begin{array}{c}0.204^{* * * k} \\
(0.009)\end{array}$ & $\begin{array}{c}0.167^{* * * *} \\
(0.006)\end{array}$ & & & & \\
\hline Highest Complexity & & $\begin{array}{c}0.152^{* * * *} \\
(0.030)\end{array}$ & $\begin{array}{c}0.147^{* * * *} \\
(0.029)\end{array}$ & $\begin{array}{c}0.127^{* k * k} \\
(0.025)\end{array}$ & & & & \\
\hline Physical Strength & & $\begin{array}{c}0.149^{* *} \\
(0.055)\end{array}$ & $\begin{array}{l}0.118^{*} \\
(0.057)\end{array}$ & $\begin{array}{c}0.210^{* k * k} \\
(0.037)\end{array}$ & & & & \\
\hline Observations & 3,425 & 3,425 & 3,425 & 3,424 & 3,586 & 3,762 & 3,583 & 3,762 \\
\hline Nbr. Factories & 16 & 16 & 16 & 16 & 16 & 20 & 20 & 20 \\
\hline $\begin{array}{l}\text { Factory FE } \\
\text { Machine FE }\end{array}$ & $\begin{array}{l}\text { YES } \\
\text { NO }\end{array}$ & $\begin{array}{l}\text { YES } \\
\text { NO }\end{array}$ & $\begin{array}{l}\text { YES } \\
\text { NO }\end{array}$ & $\begin{array}{l}\text { YES } \\
\text { YES }\end{array}$ & YES & YES & YES & YES \\
\hline
\end{tabular}

Notes: Columns 1-4 shows results from regressing reversed grade (7-grade) on an indicator variable for a female worker, and four measures of worker's skill or productivity. "Avg. Efficiency" is the workers average efficiency in those processes on which the worker is officially trained on. "Nbr. Processes" is the number of those processes on which the workers is officially trained on. "Highest Complexity" is the complexity of that skill among which worker is trained on that has the highest complexity on a seven-grade scale. "Physical Strength" is indicator variable on worker is trained on a skill classified as requiring physical strength. Columns 5-8 test whether there is a gender gap on any of these four skill measures. Level of observation is worker. All 
regressions control for Factory fixed effects. Standard Errors clustered at Factory level. Asterisks indicate significance at. $10(*), .05(* *)$, and $.01(* *)$ level.

Table 4: Grade Gaps with Survey Controls

$(1)$

$(2)$

(3)

(4)

$(5)$

(6)

\begin{tabular}{|c|c|c|c|c|c|c|}
\hline \multirow[t]{3}{*}{ Dep. Variable } & \multicolumn{2}{|c|}{ (Reverse) Grade: } & \multirow{3}{*}{ Grades 6-3 } & \multirow{3}{*}{ Grades 7-3 } & \multirow{3}{*}{$\begin{array}{c}\text { Grades } 7-3 \\
\text { Fact.Ten. }\end{array}$} & \multirow{3}{*}{$\begin{array}{c}\text { Grades } 7-3 \\
\text { Adj.Sect.Ten. }\end{array}$} \\
\hline & Grades 6-3 & Grades 6-3 & & & & \\
\hline & & & & & & \\
\hline Female Worker & $\begin{array}{c}-0.376^{* * *} \\
(0.054)\end{array}$ & $\begin{array}{c}-0.252^{* * *} \\
(0.045)\end{array}$ & $\begin{array}{c}-0.237^{* * *} \\
(0.047)\end{array}$ & $\begin{array}{c}-0.800^{* * *} \\
(0.102)\end{array}$ & $\begin{array}{c}-0.401^{* * *} \\
(0.063)\end{array}$ & $\begin{array}{c}-0.439^{* * *} \\
(0.067)\end{array}$ \\
\hline Years in Sector & & $\begin{array}{c}0.200^{* * *} \\
(0.018)\end{array}$ & $\begin{array}{c}0.203^{* * *} \\
(0.019)\end{array}$ & & $\begin{array}{c}0.467^{* * *} \\
(0.030)\end{array}$ & $\begin{array}{c}0.446^{* * *} \\
(0.028)\end{array}$ \\
\hline Years in Sector ${ }^{2}$ & & $\begin{array}{c}-0.006^{* * *} \\
(0.001)\end{array}$ & $\begin{array}{c}-0.006^{* * *} \\
(0.001)\end{array}$ & & $\begin{array}{c}-0.017^{* * *} \\
(0.002)\end{array}$ & $\begin{array}{c}-0.016^{* * *} \\
(0.002)\end{array}$ \\
\hline Years in Factory & & & $\begin{array}{c}0.058^{* *} \\
(0.024)\end{array}$ & & & \\
\hline Years per Factory & & & $\begin{array}{c}-0.044^{* * *} \\
(0.014)\end{array}$ & & & \\
\hline Age & & & $\begin{array}{l}-0.002 \\
(0.005)\end{array}$ & & & \\
\hline Education & & & $\begin{array}{c}0.020^{* * *} \\
(0.006)\end{array}$ & & & \\
\hline Observations & 2,175 & 2,175 & 2,175 & 2,909 & 2,909 & 2,909 \\
\hline Nbr. Factories & 71 & 71 & 71 & 71 & 71 & 71 \\
\hline Factory-FE & YES & YES & YES & YES & YES & YES \\
\hline
\end{tabular}

Notes: Columns 1-3 show results from regressing reversed grade (7-grade) of workers on an indicator variable for a female worker, and worker observables from survey of representative set of sewing workers of grades 6-3. "Years in Sector" is years worked in any garment factory in the country, "Years in Factory" is years worked in current factory, while "Years per Factory" is years in the sector divided by number of factories worked in. Columns 4-5 add sampled observations from grade 7 workers from HR data, such that share of sampled grade 7 workers in combined dataset is equal to their share in the overall HR data, and uses factory tenure for the grade 7 workers as sector tenure. Colum 6 shows same specification as column 5 , but for grade 7 workers instead uses simulated sector tenure values, with the simulation approach explained in Appendix B. Level of observation is on the worker level. All regressions control for factory fixed effects. Standard Errors clustered at Factory level. Asterisks indicate significance at the $.10(*), .05(* *)$, and $.01(* * *)$ levels. 
Table 5: Internal and External Promotion Rates (Monthly)

\begin{tabular}{|c|c|c|c|c|c|}
\hline & \multicolumn{3}{|c|}{ HR Pay-roll data statistics: } & \multicolumn{2}{|c|}{ Fitted model parameters: } \\
\hline & \multicolumn{3}{|c|}{ Internal Promotion Rates: } & \multicolumn{2}{|c|}{ External Promotion Rates: } \\
\hline & Men & Diff. & $\begin{array}{l}\text { le Workers } \\
\text { act.-Month FE }\end{array}$ & Men & Diff. Female \\
\hline Grade 3 & 0.0016 & $-0.0023^{* *}$ & $-0.0006^{* *}$ & - & - \\
\hline Grade 4 & 0.0054 & -0.0005 & $-0.0028^{* * *}$ & -0.0004 & -0.0006 \\
\hline Grade 5 & 0.0128 & -0.0027 & $-0.0057^{* * *}$ & 0.0148 & -0.0039 \\
\hline Grade 6 & 0.0200 & -0.0046 & $-0.0070^{* * *}$ & 0.0184 & -0.0032 \\
\hline Grade 7 & 0.0225 & $-0.0082^{* * *}$ & $-0.0096^{* * *}$ & 0.0268 & -0.0113 \\
\hline Overall & 90 & +0.010 & -0.0007 & 0.0082 & +0.0009 \\
\hline
\end{tabular}

Notes: First three columns show internal promotion rates estimated directly from the HR data for men, and the difference between those for men and women, for each grade between 3-7, and overall. While the second column shows raw differences, the third shows coefficients from regressions of promotion rates on female indicator variable, controlling for factory-month fixed effects. The fourth and fifth column show fitted parameter values from the model (described in more detail in Appendix D), for external promotion rates on grades 4-7, and their average weighted by the number of male of female workers on each grade, and the difference of these numbers between male and female workers. The model does not provide estimates for (external) promotion rates out of grade 3 to grade 2, as we lack necessary data from grade 2 workers. Average over external rates imputes external rate of 0 for grade 3, thus average can be interpreted as lower bound (likely highly binding for women, as few women advance beyond grade 3 in sector). The statistical significance of differences of internal promotion rates based on standard errors clustered at factory level. 
Table 6: Selection out of Sector

\begin{tabular}{|c|c|c|c|c|c|c|}
\hline & (1) & (2) & (3) & (4) & (5) & $(6)$ \\
\hline Dep. Variable & Education & Education & Married & Married & Child & Child \\
\hline Grade 3, Male & $\begin{array}{c}0.305 \\
(0.233)\end{array}$ & $\begin{array}{c}0.307 \\
(0.234)\end{array}$ & $\begin{array}{c}-0.015 \\
(0.036)\end{array}$ & $\begin{array}{c}-0.021 \\
(0.036)\end{array}$ & $\begin{array}{c}-0.048 \\
(0.056)\end{array}$ & $\begin{array}{c}-0.155 \\
(0.121)\end{array}$ \\
\hline Grade 3, Male x Sur. Year & & $\begin{array}{l}-0.012 \\
(0.217)\end{array}$ & & $\begin{array}{l}-0.022 \\
(0.033)\end{array}$ & & $\begin{array}{c}0.120 \\
(0.129)\end{array}$ \\
\hline Grade 3, Female & $\begin{array}{c}-0.237 \\
(0.181)\end{array}$ & $\begin{array}{l}-0.246 \\
(0.183)\end{array}$ & $\begin{array}{c}-0.051^{*} \\
(0.028)\end{array}$ & $\begin{array}{l}-0.055^{*} \\
(0.028)\end{array}$ & $\begin{array}{l}-0.037 \\
(0.037)\end{array}$ & $\begin{array}{c}0.026 \\
(0.075)\end{array}$ \\
\hline Grade 3, Female x Sur. Year & & $\begin{array}{c}0.112 \\
(0.174)\end{array}$ & & $\begin{array}{c}-0.022 \\
(0.027)\end{array}$ & & $\begin{array}{l}-0.081 \\
(0.082)\end{array}$ \\
\hline Survey Year & & $\begin{array}{l}-0.030 \\
(0.124)\end{array}$ & & $\begin{array}{c}0.060^{* * *} \\
(0.019)\end{array}$ & & $\begin{array}{c}0.047 \\
(0.071)\end{array}$ \\
\hline Survey Year x Female & & $\begin{array}{c}0.002 \\
(0.143)\end{array}$ & & $\begin{array}{l}-0.032 \\
(0.022)\end{array}$ & & $\begin{array}{l}-0.020 \\
(0.078)\end{array}$ \\
\hline Year of Birth & $\begin{array}{c}0.123 \\
(0.119)\end{array}$ & $\begin{array}{c}0.126 \\
(0.119)\end{array}$ & $\begin{array}{c}-0.212^{* * *} \\
(0.018)\end{array}$ & $\begin{array}{c}-0.218^{* * *} \\
(0.018)\end{array}$ & $\begin{array}{c}-0.206^{* * *} \\
(0.029)\end{array}$ & $\begin{array}{c}-0.208^{* * *} \\
(0.029)\end{array}$ \\
\hline Year of Birth x Female & $\begin{array}{c}0.475^{* * *} \\
(0.134)\end{array}$ & $\begin{array}{c}0.475^{* * *} \\
(0.134)\end{array}$ & $\begin{array}{c}0.109^{* * *} \\
(0.021)\end{array}$ & $\begin{array}{c}0.111^{* * * *} \\
(0.021)\end{array}$ & $\begin{array}{c}0.035 \\
(0.032)\end{array}$ & $\begin{array}{c}0.036 \\
(0.032)\end{array}$ \\
\hline Female & $\begin{array}{c}-0.410^{* * *} \\
(0.140)\end{array}$ & $\begin{array}{c}-0.409^{* * *} \\
(0.141)\end{array}$ & $\begin{array}{c}0.135^{* * *} \\
(0.022)\end{array}$ & $\begin{array}{c}0.131^{* * * *} \\
(0.022)\end{array}$ & $\begin{array}{c}0.085^{* *} \\
(0.034)\end{array}$ & $\begin{array}{c}0.102 \\
(0.069)\end{array}$ \\
\hline Constant (Male Avg.) & $\begin{array}{c}6.108^{* * *} \\
(0.122)\end{array}$ & $\begin{array}{c}6.105^{* * *} \\
(0.123)\end{array}$ & $\begin{array}{c}0.687^{* * *} \\
(0.019)\end{array}$ & $\begin{array}{c}0.693^{* * *} \\
(0.019)\end{array}$ & $\begin{array}{c}0.689^{* * *} \\
(0.031)\end{array}$ & $\begin{array}{c}0.653^{* * *} \\
(0.063)\end{array}$ \\
\hline Observations & 2,182 & 2,182 & 2,196 & 2,196 & 1,037 & 1,037 \\
\hline Nbr. Factories & 71 & 71 & 71 & 71 & 48 & 48 \\
\hline
\end{tabular}

Notes: Table shows regressions of years of education, marriage status and parental status on female worker indicator variable, and an indicator variable for the worker bding on the hightest (nonsupervisory) grade 3 , and interacted again with female worker variable, and controlling for birth year, again separately for men and women. Columns 2, 4 and 6 interact variables for being on grade 3 with survey year variables, for outcome variables education, mbeing married and having children, respectively. Asterisks indicate significance at $.10(*), .05(* *)$, and $.01(* * *)$ level. 
Table 7: Internal Promotions with Worker Skill Data

(1)

(2)

(3)

(4)

(5)

(6)

(7)

(8)

\begin{tabular}{|c|c|c|c|c|c|c|c|c|}
\hline Dep. Variable & $\begin{array}{l}\text { Avg. } \\
\text { Effic. }\end{array}$ & $\begin{array}{c}\text { Nbr. } \\
\text { Process. }\end{array}$ & $\begin{array}{l}\text { Highest } \\
\text { Complex. }\end{array}$ & $\begin{array}{l}\text { Phys. } \\
\text { Strength }\end{array}$ & Internal & Promoti & ons: & \\
\hline Female Worker & $\begin{array}{c}0.030 \\
(0.068)\end{array}$ & $\begin{array}{l}-0.009 \\
(0.054)\end{array}$ & $\begin{array}{c}-0.334^{* * *} \\
(0.050)\end{array}$ & $\begin{array}{c}-0.292^{* * * *} \\
(0.035)\end{array}$ & $\begin{array}{c}-0.647^{* *} \\
(0.265)\end{array}$ & & $\begin{array}{c}-0.389^{*} \\
(0.210)\end{array}$ & $\begin{array}{l}-0.289 \\
(0.204)\end{array}$ \\
\hline Avg. Efficiency & & & & & & $\begin{array}{c}0.347 \\
(0.219)\end{array}$ & $\begin{array}{c}0.346 \\
(0.220)\end{array}$ & $\begin{array}{c}0.331 \\
(0.206)\end{array}$ \\
\hline Nbr. Processes & & & & & & $\begin{array}{l}-0.090 \\
(0.111)\end{array}$ & $\begin{array}{c}-0.083 \\
(0.111)\end{array}$ & $\begin{array}{c}-0.157^{*} \\
(0.085)\end{array}$ \\
\hline Highest Complexity & & & & & & $\begin{array}{c}0.574^{* *} \\
(0.196)\end{array}$ & $\begin{array}{c}0.568^{* *} \\
(0.197)\end{array}$ & $\begin{array}{c}0.550^{* * *} \\
(0.181)\end{array}$ \\
\hline Physical Strength & & & & & & $\begin{array}{c}0.262 \\
(0.215)\end{array}$ & $\begin{array}{c}0.218 \\
(0.208)\end{array}$ & $\begin{array}{l}-0.011 \\
(0.197)\end{array}$ \\
\hline Observations & 3,586 & 3,762 & 3,583 & 3,762 & 3,371 & 3,371 & 3,371 & 3,370 \\
\hline Nbr. Factories & 16 & 20 & 20 & 20 & 16 & 16 & 16 & 16 \\
\hline Factory FE & YES & YES & YES & YES & YES & YES & YES & YES \\
\hline Grade FE & YES & YES & YES & YES & YES & YES & YES & YES \\
\hline Machine FE & & & & & NO & NO & NO & YES \\
\hline
\end{tabular}

Notes: Columns 1-4 regress four main skills measures on female worker dummy, controlling for grade fixed effects. Columns 5-8 show results from regressing internal regressions in the sample of workers from HR data with skill data available, on four main skill variables. "Avg. Efficiency" is the workers average efficiency in those processes on which the worker is officially trained on. "Nbr. Processes" is the number of those processes on which the workers is officially trained on. "Highest Complexity" is the complexity of that skill among which worker is trained on that has the highest complexity on a seven-grade scale. "Physical Strength" is indicator variable on worker is trained on a skill classified as requiring physical strength. Level of observation are individual workers. All regressions control for Factory and grade fixed effects. Standard Errors clustered at Factory level. Asterisks indicate significance at. $10(*), .05(* *)$, and $.01(* * *)$ level. 
Table 8: Grade and Promotion Gaps, and Marriage Status

\begin{tabular}{|c|c|c|c|c|c|c|c|c|c|}
\hline & $(1)$ & $(2)$ & $(3)$ & $(4)$ & $(5)$ & (6) & (7) & $(8)$ & (9) \\
\hline Dep. Variable: & (Reverse) & Grade: & & Internal & Promotions & & Years pe & Factory: & \\
\hline Female Worker & $\begin{array}{c}-0.237^{* * *} \\
(0.047)\end{array}$ & $\begin{array}{c}-0.237^{* * *} \\
(0.046)\end{array}$ & $\begin{array}{c}-0.221^{* * *} \\
(0.083)\end{array}$ & $\begin{array}{c}-0.377^{* * *} \\
(0.136)\end{array}$ & $\begin{array}{c}-0.384^{* * *} \\
(0.134)\end{array}$ & $\begin{array}{l}-0.201 \\
(0.193)\end{array}$ & $\begin{array}{c}0.698^{* * *} \\
(0.145)\end{array}$ & $\begin{array}{c}0.716^{* * *} \\
(0.147)\end{array}$ & $\begin{array}{c}0.455^{* * *} \\
(0.137)\end{array}$ \\
\hline Years in Sector & $\begin{array}{c}0.203^{* * *} \\
(0.019)\end{array}$ & $\begin{array}{c}0.203^{* * *} \\
(0.019)\end{array}$ & $\begin{array}{c}0.203^{* * *} \\
(0.019)\end{array}$ & $\begin{array}{c}0.060 \\
(0.057)\end{array}$ & $\begin{array}{c}0.059 \\
(0.056)\end{array}$ & $\begin{array}{c}0.059 \\
(0.056)\end{array}$ & $\begin{array}{c}0.230^{* * *} \\
(0.077)\end{array}$ & $\begin{array}{c}0.232^{* * *} \\
(0.077)\end{array}$ & $\begin{array}{c}0.233^{* * *} \\
(0.077)\end{array}$ \\
\hline Years in Sector ${ }^{2}$ & $\begin{array}{c}-0.006^{* * *} \\
(0.001)\end{array}$ & $\begin{array}{c}-0.006^{* * *} \\
(0.001)\end{array}$ & $\begin{array}{c}-0.006^{* * *} \\
(0.001)\end{array}$ & $\begin{array}{l}-0.000 \\
(0.002)\end{array}$ & $\begin{array}{l}-0.000 \\
(0.003)\end{array}$ & $\begin{array}{l}-0.000 \\
(0.003)\end{array}$ & $\begin{array}{c}0.005 \\
(0.006)\end{array}$ & $\begin{array}{c}0.005 \\
(0.006)\end{array}$ & $\begin{array}{c}0.005 \\
(0.006)\end{array}$ \\
\hline Years in Factory & $\begin{array}{c}0.058^{* *} \\
(0.024)\end{array}$ & $\begin{array}{c}0.058^{* *} \\
(0.024)\end{array}$ & $\begin{array}{c}0.058^{* *} \\
(0.024)\end{array}$ & $\begin{array}{c}0.035 \\
(0.027)\end{array}$ & $\begin{array}{c}0.036 \\
(0.027)\end{array}$ & $\begin{array}{c}0.036 \\
(0.027)\end{array}$ & & & \\
\hline Years per Factory & $\begin{array}{c}-0.044^{* * *} \\
(0.014)\end{array}$ & $\begin{array}{c}-0.044^{* * *} \\
(0.014)\end{array}$ & $\begin{array}{c}-0.044^{* * *} \\
(0.014)\end{array}$ & $\begin{array}{c}-0.063^{* *} \\
(0.024)\end{array}$ & $\begin{array}{c}-0.064^{* * *} \\
(0.024)\end{array}$ & $\begin{array}{c}-0.062^{* *} \\
(0.024)\end{array}$ & & & \\
\hline Age & $\begin{array}{c}-0.002 \\
(0.005)\end{array}$ & $\begin{array}{l}-0.002 \\
(0.005)\end{array}$ & $\begin{array}{c}-0.002 \\
(0.005)\end{array}$ & $\begin{array}{l}-0.019 \\
(0.014)\end{array}$ & $\begin{array}{l}-0.021 \\
(0.016)\end{array}$ & $\begin{array}{l}-0.021 \\
(0.016)\end{array}$ & $\begin{array}{c}0.028^{* * *} \\
(0.009)\end{array}$ & $\begin{array}{c}0.033^{* * *} \\
(0.010)\end{array}$ & $\begin{array}{c}0.033^{* * *} \\
(0.010)\end{array}$ \\
\hline Education & $\begin{array}{c}0.020^{* * *} \\
(0.006)\end{array}$ & $\begin{array}{c}0.020^{* * *} \\
(0.006)\end{array}$ & $\begin{array}{c}0.020^{* * *} \\
(0.006)\end{array}$ & $\begin{array}{c}0.001 \\
(0.021)\end{array}$ & $\begin{array}{c}0.002 \\
(0.019)\end{array}$ & $\begin{array}{c}0.002 \\
(0.019)\end{array}$ & $\begin{array}{c}-0.017 \\
(0.018)\end{array}$ & $\begin{array}{c}-0.020 \\
(0.018)\end{array}$ & $\begin{array}{l}-0.020 \\
(0.019)\end{array}$ \\
\hline Married & & $\begin{array}{l}-0.003 \\
(0.044)\end{array}$ & & & $\begin{array}{c}0.068 \\
(0.162)\end{array}$ & & & $\begin{array}{l}-0.169 \\
(0.112)\end{array}$ & \\
\hline Married x Male & & & $\begin{array}{c}0.012 \\
(0.074)\end{array}$ & & & $\begin{array}{c}0.234 \\
(0.235)\end{array}$ & & & $\begin{array}{c}-0.405^{* *} \\
(0.188)\end{array}$ \\
\hline Married x Female & & & $\begin{array}{l}-0.010 \\
(0.048)\end{array}$ & & & $\begin{array}{l}-0.016 \\
(0.175)\end{array}$ & & & $\begin{array}{l}-0.050 \\
(0.147)\end{array}$ \\
\hline Observations & 2,175 & 2,175 & 2,175 & 2,151 & 2,151 & 2,151 & 2,175 & 2,175 & 2,175 \\
\hline Nbr. Factories & 71 & 71 & 71 & 71 & 71 & 71 & 71 & 71 & 71 \\
\hline Factory-FE & YES & YES & YES & YES & YES & YES & YES & YES & YES \\
\hline Grade-FE & NO & NO & NO & YES & YES & YES & YES & YES & YES \\
\hline
\end{tabular}

Notes: Table shows results from regressing current reverse grade (7-grade) in columns 1-3, internal promotion rates of workers (the difference between the current and next month's grade of a worker, multiplied by 12 ) in columns $4-6$, and the ratio of years worked in the sector over numbers of factories a worker has worked in ("Years per Factory") in columns 7-9, on an indicator variable for a female worker, and worker observables from survey of representative set of sewing workers of grades 6-3. "Years in Sector" is years worked in any garment factory in the country, while "Years in Factory" is years worked in current factory. Level of observation is worker level. All regressions control for factory, and columns 4-9 also grade fixed effects. Standard Errors clustered at factory level. Asterisks indicate significance at the $.10\left(^{*}\right), .05(* *)$, and $.01(* * *)$ levels. 
Table 9: Grade and Promotion Gaps, and Children

\begin{tabular}{|c|c|c|c|c|c|c|c|c|c|}
\hline & $(1)$ & $(2)$ & $(3)$ & (4) & $(5)$ & (6) & $(7)$ & (8) & $(9)$ \\
\hline Dep. Variable: & (Reverse) & Grade: & & Internal & Promoti & as: & Years pe & Factory: & \\
\hline Female Worker & $\begin{array}{c}-0.197^{* * *} \\
(0.067)\end{array}$ & $\begin{array}{c}-0.135^{*} \\
(0.068)\end{array}$ & $\begin{array}{c}-0.289^{* *} \\
(0.139)\end{array}$ & $\begin{array}{c}-0.617^{* * *} \\
(0.262)\end{array}$ & $\begin{array}{c}-0.566^{* *} \\
(0.248)\end{array}$ & $\begin{array}{c}-0.718^{*} \\
(0.388)\end{array}$ & $\begin{array}{c}0.911^{* * * *} \\
(0.327)\end{array}$ & $\begin{array}{c}0.796^{* *} \\
(0.314)\end{array}$ & $\begin{array}{c}0.880^{* *} \\
(0.363)\end{array}$ \\
\hline Years in Sector & $\begin{array}{c}0.231^{* * *} \\
(0.026)\end{array}$ & $\begin{array}{c}0.230^{* * *} \\
(0.027)\end{array}$ & $\begin{array}{c}0.229^{* * *} \\
(0.026)\end{array}$ & $\begin{array}{c}0.078 \\
(0.126)\end{array}$ & $\begin{array}{c}0.084 \\
(0.127)\end{array}$ & $\begin{array}{c}0.086 \\
(0.124)\end{array}$ & $\begin{array}{c}0.277^{* *} \\
(0.125)\end{array}$ & $\begin{array}{c}0.273^{* *} \\
(0.122)\end{array}$ & $\begin{array}{c}0.266^{* *} \\
(0.124)\end{array}$ \\
\hline Years in Sector ${ }^{2}$ & $\begin{array}{c}-0.007^{* * *} \\
(0.002)\end{array}$ & $\begin{array}{c}-0.007^{* * *} \\
(0.002)\end{array}$ & $\begin{array}{c}-0.007^{* * *} \\
(0.002)\end{array}$ & $\begin{array}{c}0.001 \\
(0.005)\end{array}$ & $\begin{array}{c}0.001 \\
(0.005)\end{array}$ & $\begin{array}{c}0.001 \\
(0.005)\end{array}$ & $\begin{array}{c}-0.001 \\
(0.010)\end{array}$ & $\begin{array}{c}-0.000 \\
(0.010)\end{array}$ & $\begin{array}{c}-0.000 \\
(0.010)\end{array}$ \\
\hline Years in Factory & $\begin{array}{c}0.039 \\
(0.024)\end{array}$ & $\begin{array}{c}0.042^{*} \\
(0.023)\end{array}$ & $\begin{array}{c}0.041^{*} \\
(0.023)\end{array}$ & $\begin{array}{c}0.015 \\
(0.046)\end{array}$ & $\begin{array}{c}0.016 \\
(0.047)\end{array}$ & $\begin{array}{c}0.017 \\
(0.049)\end{array}$ & & & \\
\hline Years per Factory & $\begin{array}{c}-0.024 \\
(0.017)\end{array}$ & $\begin{array}{c}-0.023 \\
(0.017)\end{array}$ & $\begin{array}{c}-0.023 \\
(0.017)\end{array}$ & $\begin{array}{c}-0.063 \\
(0.042)\end{array}$ & $\begin{array}{c}-0.066 \\
(0.041)\end{array}$ & $\begin{array}{c}-0.066 \\
(0.042)\end{array}$ & & & \\
\hline Age & $\begin{array}{l}-0.005 \\
(0.009)\end{array}$ & $\begin{array}{c}0.009 \\
(0.010)\end{array}$ & $\begin{array}{c}0.008 \\
(0.009)\end{array}$ & $\begin{array}{c}-0.048 \\
(0.036)\end{array}$ & $\begin{array}{l}-0.026 \\
(0.029)\end{array}$ & $\begin{array}{c}-0.026 \\
(0.028)\end{array}$ & $\begin{array}{c}0.043^{* *} \\
(0.017)\end{array}$ & $\begin{array}{c}0.031^{*} \\
(0.018)\end{array}$ & $\begin{array}{c}0.030 \\
(0.018)\end{array}$ \\
\hline Education & $\begin{array}{c}0.035^{* * *} \\
(0.009)\end{array}$ & $\begin{array}{c}0.030^{* * *} \\
(0.009)\end{array}$ & $\begin{array}{c}0.031^{* * *} \\
(0.009)\end{array}$ & $\begin{array}{c}-0.017 \\
(0.035)\end{array}$ & $\begin{array}{l}-0.023 \\
(0.036)\end{array}$ & $\begin{array}{c}-0.023 \\
(0.034)\end{array}$ & $\begin{array}{c}-0.036 \\
(0.030)\end{array}$ & $\begin{array}{c}-0.030 \\
(0.030)\end{array}$ & $\begin{array}{c}-0.026 \\
(0.030)\end{array}$ \\
\hline Married & $\begin{array}{c}0.066 \\
(0.134)\end{array}$ & $\begin{array}{c}0.055 \\
(0.138)\end{array}$ & $\begin{array}{c}0.062 \\
(0.137)\end{array}$ & $\begin{array}{c}-0.153 \\
(0.308)\end{array}$ & $\begin{array}{l}-0.121 \\
(0.297)\end{array}$ & $\begin{array}{c}-0.125 \\
(0.300)\end{array}$ & $\begin{array}{c}-0.270 \\
(0.712)\end{array}$ & $\begin{array}{c}-0.172 \\
(0.704)\end{array}$ & $\begin{array}{c}-0.145 \\
(0.703)\end{array}$ \\
\hline Child & & $\begin{array}{c}-0.297^{* * *} \\
(0.078)\end{array}$ & $\begin{array}{c}-0.637^{* * *} \\
(0.181)\end{array}$ & & $\begin{array}{c}-0.517 \\
(0.355)\end{array}$ & $\begin{array}{c}-0.661 \\
(0.656)\end{array}$ & & $\begin{array}{c}0.161 \\
(0.157)\end{array}$ & $\begin{array}{c}-0.170 \\
(0.384)\end{array}$ \\
\hline Child under 5 & & $\begin{array}{c}0.211^{* * *} \\
(0.073)\end{array}$ & $\begin{array}{c}0.466^{* * *} \\
(0.165)\end{array}$ & & $\begin{array}{c}0.051 \\
(0.139)\end{array}$ & $\begin{array}{c}0.035 \\
(0.529)\end{array}$ & & $\begin{array}{c}-0.538^{* * *} \\
(0.157)\end{array}$ & $\begin{array}{c}0.058 \\
(0.380)\end{array}$ \\
\hline Child x Female & & & $\begin{array}{c}0.417^{* *} \\
(0.186)\end{array}$ & & & $\begin{array}{c}0.187 \\
(0.552)\end{array}$ & & & $\begin{array}{c}0.377 \\
(0.408)\end{array}$ \\
\hline Child under 5 x Fem. & & & $\begin{array}{l}-0.301^{*} \\
(0.180)\end{array}$ & & & $\begin{array}{c}0.034 \\
(0.615)\end{array}$ & & & $\begin{array}{l}-0.739 \\
(0.447)\end{array}$ \\
\hline $\begin{array}{l}\text { Observations } \\
\text { Nbr. Factories }\end{array}$ & $\begin{array}{c}1,028 \\
48\end{array}$ & $\begin{array}{c}1,028 \\
48\end{array}$ & $\begin{array}{c}1,028 \\
48\end{array}$ & $\begin{array}{c}1,009 \\
48\end{array}$ & $\begin{array}{c}1,009 \\
48\end{array}$ & $\begin{array}{c}1,009 \\
48\end{array}$ & $\begin{array}{c}1,028 \\
48\end{array}$ & $\begin{array}{c}1,028 \\
48\end{array}$ & $\begin{array}{c}1,028 \\
48\end{array}$ \\
\hline $\begin{array}{l}\text { Factory-FE } \\
\text { Grade FE }\end{array}$ & $\begin{array}{l}\text { YES } \\
\text { NO }\end{array}$ & $\begin{array}{l}\text { YES } \\
\text { NO }\end{array}$ & $\begin{array}{l}\text { YES } \\
\text { NO }\end{array}$ & $\begin{array}{l}\text { YES } \\
\text { YES }\end{array}$ & $\begin{array}{l}\text { YES } \\
\text { YES }\end{array}$ & $\begin{array}{l}\text { YES } \\
\text { YES }\end{array}$ & $\begin{array}{l}\text { YES } \\
\text { YES }\end{array}$ & $\begin{array}{l}\text { YES } \\
\text { YES }\end{array}$ & $\begin{array}{l}\text { YES } \\
\text { YES }\end{array}$ \\
\hline
\end{tabular}

Notes: Outcome variable is current reverse grade (7-grade) in columns 1-3, internal promotion rates of workers (the difference between the current and next month's grade of a worker, multiplied by 12) in columns 4-6, and the ratio of years worked in the sector over numbers of factories a worker has worked in ("Years per Factory") in columns 7-9. Independent variables are an indicator variable for a female worker, and worker observables from survey of representative set of sewing workers of grades 6-3 from 45 factories at which information on children is available in surveys. "Years in Sector" is years worked in any garment factory in the country, while "Years in Factory" is years worked in current factory. "Child" is indicator variable for having any child, and "child under 5" for having any child younger than 5 years old. Level of observation is worker level. All regressions control for factory, and columns 4-12 also grade fixed effects. Standard Errors clustered at factory level. Asterisks indicate significance at the $.10\left({ }^{*}\right), .05\left({ }^{* *}\right)$, and $.01(* * *)$ levels. 


\section{Table 10: Return to Skills}

Dep. Variable

Log Wage:

\begin{tabular}{|c|c|c|c|}
\hline Avg. Efficiency & $\begin{array}{c}0.013^{* * *} \\
(0.004)\end{array}$ & $\begin{array}{c}0.012 * * * \\
(0.004)\end{array}$ & $\begin{array}{c}0.012^{* * *} \\
(0.003)\end{array}$ \\
\hline Nbr. Processes & $\begin{array}{c}0.016^{* * *} \\
(0.001)\end{array}$ & $\begin{array}{c}0.020 * * * \\
(0.004)\end{array}$ & $\begin{array}{c}0.017^{* * *} * \\
(0.001)\end{array}$ \\
\hline Highest Complexity & $\begin{array}{c}0.012^{* * *} * \\
(0.003)\end{array}$ & $\begin{array}{c}0.021 * * * \\
(0.006)\end{array}$ & $\begin{array}{c}0.022^{* * *} \\
(0.003)\end{array}$ \\
\hline Physical Strength & $\begin{array}{c}0.015^{* * *} \\
(0.003)\end{array}$ & $\begin{array}{c}0.013 \\
(0.007)\end{array}$ & $\begin{array}{l}0.013^{*} \\
(0.007)\end{array}$ \\
\hline Avg. Efficiency x Female & & $\begin{array}{c}0.002 \\
(0.020)\end{array}$ & \\
\hline Nbr. Processes x Female & & $\begin{array}{l}-0.001 \\
(0.001)\end{array}$ & \\
\hline Highest Complexity x Female & & $\begin{array}{l}-0.005 \\
(0.003)\end{array}$ & $\begin{array}{c}-0.005^{* * *} \\
(0.001)\end{array}$ \\
\hline Physical Strength x Female & & $\begin{array}{l}-0.001 \\
(0.009)\end{array}$ & $\begin{array}{c}-0.002 \\
(0.009)\end{array}$ \\
\hline Observations & 3,424 & 3,424 & 3,424 \\
\hline Nbr. Factories & 16 & 16 & 16 \\
\hline Factory FE & YES & YES & YES \\
\hline
\end{tabular}

Notes: Results from regressing log wage, in the sample of workers from HR data with skill data available, on four main skill variables, and its interactions with female worker indicator. "Avg. Efficiency" is the workers average efficiency in those processes on which the worker is officially trained on. "Nbr. Processes" is the number of those processes on which the workers is officially trained on. "Highest Complexity" is the complexity of that skill among which worker is trained on that has the highest complexity on a seven-grade scale. "Physical Strength" is indicator variable on worker is trained on a skill classified as requiring physical strength. Level of observation is worker-month level in columns 1-3. All regressions control for Factory fixed effects. Standard Errors clustered at Factory level. Asterisks indicate significance at. $10(*), .05(* *)$, and $.01(* * *)$ level. 


\section{Appendix A: The Wage Gap, Worker Absenteeism and Overtime:}

For different sub-sets of the 70 factories in our main sample, the HR data included detailed data on days absent, the attendance bonus earned, and the number of overtime hours worked, on the worker-month level. Attendance bonus is a monthly payment to workers who missed no more than a specified number of workdays in a month, usually either one or two days. These attendance bonuses are typically around 5 percent of the overall monthly pay of a worker.

In Table A.1, we regress these three variables on an indicator variable for female worker, controlling for factory, month, and grade fixed effects, on the worker-month level. We cluster standard errors at the level of the 34 factories in the sample. We can see that women miss on average 0.34 fewer days per month (of a mean of 0.67 absent days and a median of 0 ), earn on average 11.5 BDT higher attendance bonus per month (of a mean absent bonus of 336, or median of 400 ( $\sim$ US\$ 4.8)), and work 2.37 overtime hours less per month (of a mean of 50.6 hours and a median of 50 hours). All differences are statistically significant.

Table A.1: Gender Differences in Absenteeism and Overtime:

\section{(1)}

(2)

\begin{tabular}{lccc}
\hline & $\begin{array}{c}\text { Absent } \\
\text { Days }\end{array}$ & $\begin{array}{c}\text { Attendance } \\
\text { Bonus }\end{array}$ & $\begin{array}{c}\text { Overtime } \\
\text { Hours }\end{array}$ \\
\hline \hline & & & \\
Female Worker & $-0.0341^{* *}$ & $11.5474^{* * *}$ & $-2.3638^{* * *}$ \\
& $(0.0154)$ & $(2.2486)$ & $(0.3324)$ \\
Observations & 522,094 & 656,612 & 346,563 \\
Nbr. Factories & 57 & 63 & 42 \\
Factory \& Month FE & YES & YES & YES \\
Grade FE & YES & YES & YES \\
\hline
\end{tabular}

Notes: Column 1 shows regression of number of days worker was absent in a given month on dummy variable for female worker, while in column 2 the outcome variable is earned attendance bonuses (in BDT) by workers in a given month, and in column 3 the total overtime hours worked by the worker in a given month. Level of observation is worker-month level. All regressions control for factory, month, and grade fixed effects. Standard errors clustered on the factory level: Asterisks indicate significance at the $.10(*), .05(* *)$, and .01 $(* * *)$ levels 
In Table A. 2 columns 1 and 3, we proceed to replicate columns 5 and 7 of Table 2 on the baseline grade gaps in the sample of those 34 factories for which we have both the absenteeism and overtime data in the HR data. Both the basic wage gap and the grade gap is about 20 percent smaller in this subsample of factories, among workers of grade 3 through 6 . The inclusion of these three controls does not change the estimates of the wage gap (column 2), the grade gap (column 4), or the wage gap conditional on grade fixed effects (column 6) in any significant way.

Table A.2: Absenteeism, Overtime, and the Gender Wage Gap

$\begin{array}{llll}(1) & \text { (2) } & \text { (3) }\end{array}$

\begin{tabular}{lcc|cc|cc}
\hline & \multicolumn{2}{c}{ Log Wage } & \multicolumn{2}{c}{ (Reverse) Grade } & \multicolumn{2}{c}{ Log Wage } \\
\hline \hline & & & & & & \\
Female Worker & $-0.064^{* * *}$ & $-0.064^{* * *}$ & $-0.621^{* * *}$ & $-0.628^{* * *}$ & $-0.013^{*}$ & $-0.014^{* *}$ \\
& $(0.005)$ & $(0.006)$ & $(0.080)$ & $(0.058)$ & $(0.007)$ & $(0.006)$ \\
& & & & & & \\
Absent Days & & $20.069^{* * *}$ & & $200.144^{* * *}$ & & $2.838^{*}$ \\
& & $(4.214)$ & & $(43.651)$ & & $(1.617)$ \\
Attend. Bonus & & $0.413^{* * *}$ & & $3.811^{* * *}$ & & $0.072^{* *}$ \\
& & $(0.089)$ & & $(0.902)$ & & $(0.031)$ \\
Overtime Hours & & $-0.732^{* * *}$ & & $-10.389^{* * *}$ & & 0.251 \\
& & $(0.231)$ & & $(3.100)$ & & $(0.175)$ \\
Observations & 28,107 & 28,107 & 28,165 & 28,165 & 28,107 & 28,107 \\
Nbr. Factories & 27 & 27 & 27 & 27 & 27 & 27 \\
Factory-FE & YES & YES & YES & YES & YES & YES \\
Grade FE & NO & NO & NO & NO & YES & YES \\
\hline
\end{tabular}

Notes: Regression of log base wage (Columns 1-2, and 5-6) and reverse worker Grade (Columns 3-4) on an indicator variable for female worker in those 34 factories in the sample in which consistent attendance and overtime data is available in HR data. Columns 2 and 4, respectively, control for number of days in month worker is absent, monthly levels of attendance bonuses earned, and overtime hours worker, averaged across month within workers. Columns 5-6 control for grade fixed effects. Level of observation is worker from the first month of data available from factory. All regressions control for factory and month fixed effects. Standard Errors clustered at factory level. Asterisks indicate significance at the $.10(*), .05(* *)$, and $.01(* * *)$ levels.

\section{Appendix B: Simulating Sector Tenure for Grade 7 workers sampled from HR data}

We sample 743 grade 7 workers from the HR data (81 male and 653) female. For these workers, we know factory tenure from the HR data, but we do not know sector tenure. We therefore simulate sector tenure based on the joint distribution of factory and sector tenure among grade 7 workers from a separate sample of 190 surveyed grade 7 workers from 4 factories outside the main sample of 70 factories used in this paper. The left panel in Figure B.1 shows the empirical joint distribution among these 
190 workers. To replicate this distribution among the 743 sampled workers, we use the following (non-parametric) approach. We first separate the 190 surveyed workers into ten deciles according to their reported tenure at their current factory. For each decile, we take the share of workers for whom sector and current factory tenure differs (that is, the share who have worked at another factory before). For each decile, we then calculate the ratio between sector and factory tenure for those workers for whom these two variables differ.

We then separate the 743 sampled workers from the HR data into ten bins, based on the deciles of factory tenure from the 190 surveyed workers. We randomly sample in each of the bins a share of workers equal to the decile specific-share of workers for whom sector and factory tenure differs in the survey data. For these selected workers from each bin, we obtain a simulated sector tenure by multiplying their factory tenure values with the decile-specific ratio of sector and current factory tenure from the survey data. The right hand panel of Figure B.1 plots the joint distribution of the empirical factory tenure and one iteration of simulated sector tenure, among the 743 workers sampled from the HR data, indicating that it is qualitatively similar to the joint distribution from the surveyed workers shown in the left hand panel of Figure B.1.
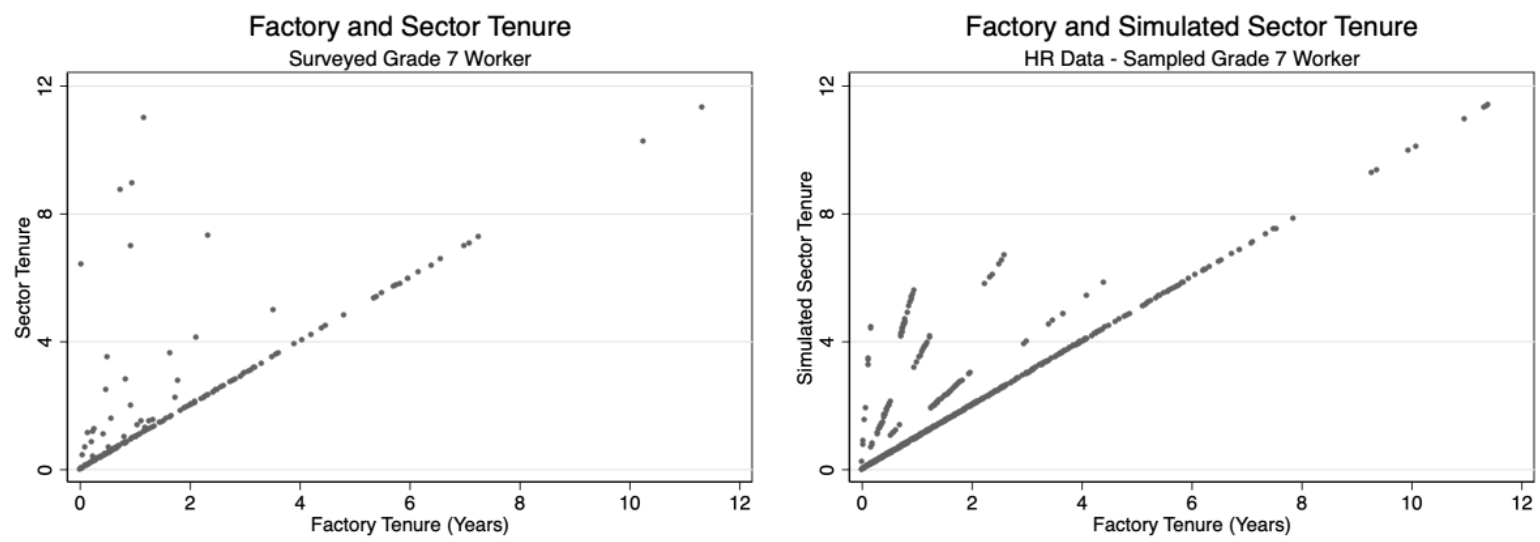

Figure B.1: Simulation of Sector Tenure for Grade 7 Workers. Left panel plots empirical joint distribution of sector tenure and tenure at current factory among a sample of 190 grade 7 workers surveyed at three factories outside of main sample of factories in this paper. Right panel shows joint distribution of simulated sector tenure and empirical factory tenure in sample of 743 grade 7 workers, randomly sampled from HR data, suing simulation algorithm laid out in Appendix B. 


\section{Appendix C: Controlling Grade Gap for Survey and Skill Observables}

Table C.1. below adds both skill and survey controls into the grade gap regression, in the sample of workers for which both types of data is available. These are 154 workers from 9 factories, 131 of which are female. Given the small sample and the large number of possible controls, overfitting of the regression may be a concern. This would overstate the share of the grade gap explained by the two sets of control variable. Therefore, we use PDS Lasso (Belloni et al. 2016), to discipline the selection of control variables from both datasets in the regression. The pool of variables from which the Lasso can chose are all variables included in Tables 3 (skill data, including machine fixed effects), 8 and 9 (survey data), and the squares of the continuous variables among them. All variables chosen by the PDS Lasso shown in Table C.1.

Column 1 shows the basic grade gap in the regression when only controlling for factory fixed effects. Column 2 adds survey based controls only, as selected by the PDS Lasso, and Column 3 skill controls only. While survey based controls explain about 25 percent of the gap in this sample alone, the two selected skill controls explain about 35 percent. Skills are positively correlated with years in sector, at least the number of processes a worker can do, though the correlation is not statistically significant (Column 4). Finally, jointly, skills and survey observable explain about 60 percent of the grade gap in this sample (column 5). Adding the skills controls to the controls for sector tenure increase the share of the grade gap that is explained by around 13 percent $((0.248-0.198) / 0.422)$. 
Table C.1 Controlling Grade Gap for Survey Observables and Skills

\begin{tabular}{|c|c|c|c|c|c|}
\hline Dep. Variable & Grade & Grade & Grade & Years/Sector & Grade \\
\hline Female Worker & $\begin{array}{l}-0.422 \\
(0.287)\end{array}$ & $\begin{array}{l}-0.313 \\
(0.240)\end{array}$ & $\begin{array}{c}-0.248 \\
(0.257)\end{array}$ & & $\begin{array}{l}-0.198 \\
(0.255)\end{array}$ \\
\hline Years in Sector & & $\begin{array}{c}0.065^{* *} \\
(0.027)\end{array}$ & & & $\begin{array}{c}0.138^{* * *} \\
(0.038)\end{array}$ \\
\hline Nbr. Factories & & $\begin{array}{c}0.092 \\
(0.077)\end{array}$ & & & \\
\hline Years in Sector ${ }^{2}$ & & & & & $\begin{array}{c}-0.005^{* *} \\
(0.002)\end{array}$ \\
\hline Nbr. Processes & & & $\begin{array}{c}0.061^{* *} \\
(0.029)\end{array}$ & $\begin{array}{c}0.026 \\
(0.053)\end{array}$ & $\begin{array}{c}0.058^{* *} \\
(0.024)\end{array}$ \\
\hline Physical Strength & & & $\begin{array}{c}0.769^{* * *} \\
(0.170)\end{array}$ & & $\begin{array}{c}0.651^{* * *} \\
(0.202)\end{array}$ \\
\hline Observations & 150 & 150 & 150 & 150 & 150 \\
\hline Nbr. Factories & 9 & 9 & 9 & 9 & 9 \\
\hline Factory-FE & YES & YES & YES & YES & YES \\
\hline Machine FE & - & - & Yes (4 sel.) & Yes (3 sel.) & Yes (5 sel.) \\
\hline
\end{tabular}

Notes: Table shows results from regressing reversed grade ( $=7$-grade) of workers on an indicator variable for a female worker, and worker observables from survey of representative set of sewing workers of grades 63 , and on four worker skill measures, from workers from those 9 factories at which survey and skill data overlap. Column 2 introduces survey controls only, column 3 skill controls only, and column 4 both. Controls from both sets of variables chosen by PDS Lasso, to prevent overfitting due to large number of control variables and small sample. "Years in Sector" is years worked in current factory, while "Years per Factory" is years in the sector divided by number of factories worked in. Level of observation is worker-month level. All regressions control for factory fixed effects. Standard Errors clustered at factory level. Asterisks indicate significance at the $.10(*), .05(* *)$, and $.01(* * *)$ levels.

\section{Appendix D: Backing out External Promotion Rates}

We would like to measure three transition rates for female and male workers: promotion within a factory, promotion by movement to a different factory, and exit from the sector. Our administrative data are at the factory level, and hence allow us to measure directly only internal promotion rates and the rate at which workers leave the factory either to work at another factory or to exit the sector. Moreover, movement to another factory may be lateral or come with a promotion. However, we also have survey data from a large sample of female and male workers that provide each worker's grade and tenure in the industry. We show here that we can back out external promotion and 
sector exit rates using only the sector tenure data for different grades and internal promotion data, and number of workers on each grade. To do this, we need to write down a model that includes external promotions and sector exit rates as parameters, and that generates at least as many moment predictions that can be matched to our data as it has parameters.

We construct an exactly identified model with 13 parameters generating predictions for 13 different moments we also observe in the data. The model can be fitted to the data separately for male and female workers. For that purpose, all parameters can be indexed by gender $\{m, f\}$. To simplify notation, however, we suppress the gender subscripts here.

Let each worker's type $k$ be indexed by the highest grade, 7 through 3 , that the worker reaches during her career in the sector. A share $s_{k}$ of workers of type $k$ on all grades $i>k$ lower than their highest ultimate grade have an (external or internal) promotion each time period. Recall that grade 7 is the entry level grade and grade 3 is the highest operator grade. So a promotion is a move from a grade $i$ to a grade $i-1$. Having reached their highest grade $i=k$, a share $p_{k}$ of workers of type $k$ exit the sector each time period. The assumption that workers of type $k$ move at a constant rate through all grades on the way to the highest grade $i=k$ is strong, but necessary for us to be able to identify unobserved overall promotion frequencies from our data.

We use these assumptions to characterize the steady state, in which the number of workers on each grade is constant over time. Assume a cohort of $M_{k}$ workers of type $k$ enter the sector each period of time at the lowest grade 7 . The number of workers of each type on each grade will remain constant only if the number exiting the grade is the same as the number entering. Let $W_{i}^{k}$ be the steady state number of workers of type $k$ on grade $i$. For $W_{i}^{k}, i<k$, to be constant, we then need $M_{k}=W_{i}^{k} s_{k}$, or $W_{i}^{k}=M_{k} / s_{k}$. Similarly, for the number of workers of type $k$ on their final grades $i=k$ to be constant we need $W_{i=k}^{k}=M_{k} / p_{k^{\prime}}$ This implies that, at any time, the number of workers $W_{i}$ on any grade $i$ is:

$$
W_{i}=\sum_{k=3}^{i} W_{i}^{k}=\left[\sum_{k=3}^{i-1} \frac{M_{k}}{s_{k}}\right]+\frac{M_{i}}{p_{i}}
$$


While we do observe the number of workers on each grade 3 through 7 in our HR data, it will be easier to target the ratio of workers on adjacent grades $i$ and $i+1$, or $r_{i, i+1}=W_{i} / W_{i+1}$. For this purpose, it will be useful to choose one worker type $k$ as the numeraire and express the size of entry cohorts of other worker types $M_{k}$ relative to the size of that cohort. Ultimately it does not matter which worker type's cohort size we choose as numeraire, but it turns out that the parameter estimates are more stable when we choose $M_{3}=1$ as the numéraire.

We can model the average and variance of sector tenure of all workers on any grade $i$ in the steady state by making additional assumptions on how the share $s_{k}$ of workers that are promoted are selected among the workers on the grade, and similarly the share $p_{k}$ among workers for whom it is the final grade. We consider three different assumptions that could be made on how this selection process works. The first assumes that all workers of type $k$ spend the same time on a given grade $i$. That is, workers exit non-final grades after exactly $1 / s_{k}$, and final grades after $1 / p_{k}$ time periods. In a crosssection of workers of a given type on a given grade in the steady state, the time these workers will have already spent on the grade will follow a uniform distribution, with mean $1 / 2 \mathrm{~s}_{\mathrm{k}}$ on non-final grades, and mean $1 / 2 p_{k}$ on final grades. We thus name this modelling option the "uniform" modeling assumption. A second possible assumption is that the workers promoted or exiting the sector are independently selected with respect to the time they already spent on the grade. This memory-less selection process will lead to an exponential distribution of time already spent on the grade among a cross section of workers of a certain type on a certain grade, with means $1 / s_{k}$ or $1 / p_{k}$. We will refer to it as the "exponential" modeling assumption. A third option assumes that the workers promoted or exiting at each period of time are selected such that the distribution of the time they have spent on the grade, at the time they exit the grade, is uniform. This implies that the exit or promotion probability strictly increases in the time workers have spent on the grade. This assumption is thereby an intermediary case between the other two cases, in which the exit or promotion probability either jumps from zero to one at one point in time (uniform assumption), or remains constant over time (exponential assumption). In a cross section of workers of a certain type on a certain grade, the third modeling option leads to a "triangular" distribution of time spent on the grade, with means $2 / 3 s_{\mathrm{k}}$ or $2 / 3 p_{k}$. 
We fit the model to the 13 data moments separately for females and males using each of the nine possible combinations of exit and promotion rules. For males, we find that only the combination of uniform promotion and exit probabilities yields parameter values in the feasible range - for example, positive values for the sector exit or promotion rates. The same combination yields feasible values for females, as does the combination of uniform promotion rates and triangular exit rates. As we will see, the latter combination is the only one that yields reasonable estimates for women.

The average tenure $T_{i}$ of workers on grade $i$ is the weighted average of the average tenures of workers of different types $k$ on grade $i$, where the weights are the number of workers of each type on the grade in the steady state. With uniform selection, this is:

$$
T_{i}=\frac{\sum_{k=3}^{i-1} \frac{M_{k}}{S_{k}}\left((7-i+0.5) \frac{1}{s_{k}}\right)+\frac{M_{i}}{p_{i}}\left((7-i) \frac{1}{s_{i}}+\frac{0.5}{p_{i}}\right)}{\sum_{k=3}^{i-1} \frac{M_{k}}{S_{k}}+\frac{M_{i}}{p_{i}}}
$$

$M_{i} / p_{i}$ is the number of worker of type $k=i$ on grade $i$ at any point in time (or their relative number if the $M_{k}$ are standardized with respect to one numéraire among them), and $(7-i) \frac{1}{s_{i}}+\frac{0.5}{p_{i}}$ is their average sector tenure. $(7-i) \frac{1}{s_{i}}$ is the time spent on average on all preceding grades on the way to grade $i$, and $0.5 / p_{i}$ is the average time spent on the final grade $i$. Similarly, $(7-i+0.5) \frac{1}{s_{k}}$ is the time spent by workers of higher types $k<i$ so far in the sector, and $M_{k} / s_{k}$ is their relative number on grade $i$.

The variance of sector tenure of all workers on a grade in the steady state, on the other hand, cannot be simply derived as the weighted average of the variances within the subsamples of workers of different types on the grade. Instead we need to use variance decomposition rules, which state that the variance of a sample is the average of the variances within all subsamples, plus the average of the squared deviations of the sub-sample means from the overall mean of the sample, with both averages weighted by the sizes of the sub-samples.

An advantage of the uniform modeling assumption is that the variance of sector tenure turns out to be equal to the variance of tenure on the current grade. This is because under the uniform assumption all workers of the same type spend the same amount of time on a given grade. So, for example, all workers of type 3 currently on grade 5 have spent the same amount of time on grades 7 and 6 , those grades they 
already have passed through. Only on grade 5 would there be variation in time spent on that grade; some have just entered it while others are already close to the time they are promoted to the next grade. This property greatly simplifies the derivation of variance of sector tenure. Note that the assumption does not hold under the exponential or triangular assumptions as these both generate variation in the time that workers of a given type have spent on previous grades. Thus, under the uniform selection assumption the variance of sector tenure of all workers on grade $i$ in the steady state is:

$$
V_{i}=\frac{\sum_{k=3}^{i-1} \frac{M_{k}}{s_{k}}\left(\frac{1}{12 s_{k}^{2}}+\left(\frac{7-i+0.5}{s_{k}}-T_{i}\right)^{2}\right)+\frac{M_{i}}{p_{i}}\left(\frac{1}{12 p_{i}^{2}}+\left(\frac{7-i}{s_{i}}+\frac{0.5}{p_{i}}-T_{i}\right)^{2}\right)}{\sum_{k=3}^{i-1} \frac{M_{k}}{S_{k}}+\frac{M_{i}}{p_{i}}}
$$

Now we have 13 unknown parameters: five sector exit probabilities for each worker type once they have reached their final grade, $p_{7}-p_{3}$; four relative sizes of each worker type (except one that is set to 1 as numéraire), $M_{7}-M_{4}$; and four promotion probabilities, $s_{6}-S_{3}$ (type 7 workers exit the sector before being promoted).

We also have 13 observed moments in the data: four ratios of workers on adjacent grades, $r_{6,7}-r_{3,4}$; five average sector tenures of workers on grades $7-3, T_{7}-T_{3}$; and four tenure variances $V_{6}-V_{3}$. The four size ratios come from factory HR records, and the sector tenure and variance data come from our surveys of workers on grades 6 through 3. A note about the average sector tenure for grade 7 (entry level) workers is merited. The grade 7 workers are not included in the surveys for the factories used in this paper. However, from surveys of grade 7 workers in four other factories, we find that only around one in eight grade 7 workers have worked in more than one factory. We set for average tenure of grade 7 workers in the sector as 125 percent of the average factory tenure of grade 7 workers, which we have from the HR data. The 25 percent adjustment factor effectively assumes that the average tenure in the prior factory is twice the average tenure in the current factory, which would be the case if time spent on these grades would follow the uniform modelling assumption. However, the results are insensitive to adjustments between 0 and 50 percent. ${ }^{34}$

\footnotetext{
${ }^{34}$ Variations in the level of this adjustments affects mainly the estimated exit rate of type 7 workers, $p_{7}$, and the estimated cohort size of type 7 workers, $M_{\%}$. But for adjustments in the range or 0 to 50 percent, these do not meaningfully affect the estimated promotion rates of the model that are shown below.
} 
We fit the predicted moments to their empirical counterparts to obtain values for the 13 parameters. We can then back out promotion rates $P_{i}$ on any grade $i$ that can be compared to the internal promotion rates from the HR data by the following equation:

$$
P_{i}=\frac{\sum_{k=3}^{i-1} \frac{M_{k}}{S_{k}} s_{k}}{W_{i}}=\frac{\sum_{k=3}^{i-1} M_{k}}{W_{i}}
$$

where $W_{i}$ is the steady state number of workers on a given grade (or relative number, due to the setting of one cohort size as numeraire), while the nominator sums over the promotion rates $s_{k}$ of workers of higher types $k<i$, weighted by their relative numbers on grade $\boldsymbol{i}$.

The first two columns of Table D.1 below show the 13 fitted parameter values under the uniform selection assumption. The promotion and sector exit rates are monthly rates. We note that while all values are positive, that is in the feasible range, for women some of the values appear unrealistically high. Specifically, promotion rates of women of type 3 are very high, implying that these women are promoted to a higher grade almost twice per month, and reach grade 3 after only little more than two months in the sector, which is clearly unrealistic. Also, more than $50 \%$ of women entering the sector are estimated to never get promoted out of the entry level position of grade 7 , which again strikes us as likely too high.

While for men the model only has feasible solutions if both promotions and sector exit are modeled under the "uniform" specification, for women the model also has a solution when modeling sector exit under the triangular model assumption, while maintaining the "uniform" assumption for selection to promotion. In this version of the model, average sector tenure of workers on grade $i$ is given by:

$$
T_{i}=\frac{\sum_{k=3}^{i-1} \frac{M_{k}}{S_{k}}\left((7-i+0.5) \frac{1}{s_{k}}\right)+\frac{M_{i}}{p_{i}}\left((7-i) \frac{1}{s_{i}}+\frac{2}{3 p_{i}}\right)}{\sum_{k=3}^{i-1} \frac{M_{k}}{S_{k}}+\frac{M_{i}}{p_{i}}}
$$

Meanwhile, the variance is given by

$$
V_{i}=\frac{\sum_{k=3}^{i-1} \frac{M_{k}}{S_{k}}\left(\frac{1}{12 s_{k}^{2}}+\left(\frac{7-i+0.5}{s_{k}}-T_{i}\right)^{2}\right)+\frac{M_{i}}{p_{i}}\left(\frac{2}{9 p_{i}^{2}}+\left(\frac{7-i}{s_{i}}+\frac{2}{3 p_{i}}-T_{i}\right)^{2}\right)}{\sum_{k=3}^{i-1} \frac{M_{k}}{S_{k}}+\frac{M_{i}}{p_{i}}}
$$


The derivation of these formulas is relatively straightforward. At the heart of the triangular assumption is that among all workers that enter a grade together, a share $e_{i}$ of the initial cohort exits the grade each period of time. Thus, after $1 / e_{i}$ time periods, all workers of that cohort have left the grade. If a cohort of size $M_{i}$ enters their final grade each period of time, $M_{i} / 2 e_{i}$ workers are present on that grade in the steady state. We have shown that the number of workers on a final grade can also be represented as $M_{i} / p_{i}$ so we have $p_{i}=2 e_{i}$. Finally, the triangular assumption leads to a distribution of time $t$ spent on the current grade in a cross section of workers, expressed by the pdf $2 e-2 e^{2} t, 0 \leq t \leq 1 / e$ (suppressing the grade index $i$ for convenience). It is easy to show that the pdf integrates to 1 over the interval $[0,1 / e]$, that its expectation is $1 / 3 e$, and its variance $1 / 18 e^{2}$. Given $p_{i}=2 e_{i}$ from above, we arrive at the average and the variance of time spent on the final grade by workers used in the equations D.5 and D.6 above. Note that as we continue to use the uniform modeling assumption for promotions, implying that all workers of the same type have spent the same amount of time on grades they already passed through, the variance of sector tenure continues to be equal to the variance of tenure on the current grade.

Fitting the model using the uniform selection assumption for promotions and the triangular selection assumption for sector exit to the data for women, we obtain parameter values that are more realistic relative to those obtained for women from the model using uniform selection for both promotion and selection. The values are shown in column 3 of Table D.1. Women of type 3 are now promoted around every 5 months, reaching grade 3 in a bit less than 2 years after entering the sector, while now only a quarter of women that enter the sector never advance out of grade 7.

Finally, Table D.2. shows the estimates we obtain for the external promotion rates based on equation D.4, and after subtracting the internal promotion rates shown in Table 5. Note that the negative values for external promotion rates on grade $4, \mathrm{P} 4$, in Table D.2 are very small in absolute values (particularly in the first and third column), and are the results of subtracting the estimated internal promotion rates, as shown in Table 5, from the backed out overall promotion rates. We regard these small negative values to be not different from zero, once possible sampling error is taken into account in both the estimated internal promotion rates and the empirical moments used to fit the model to obtain the overall promotion rates. 
Table D.1: Model Parameter Estimates

\begin{tabular}{|c|c|c|c|}
\hline & (1) & (2) & (3) \\
\hline & \multicolumn{2}{|c|}{ "Uniform" Specification } & "Triangular" Specification \\
\hline & Men & Women & Women \\
\hline \multicolumn{4}{|c|}{ Sector exit rates } \\
\hline$p_{k=3}$ & 0.0067 & 0.0054 & 0.0088 \\
\hline$p_{k=4}$ & 0.0072 & 0.0071 & 0.0117 \\
\hline$p_{k=5}$ & 0.0072 & 0.0081 & 0.0141 \\
\hline$p_{k=6}$ & 0.0091 & 0.0097 & 0.0193 \\
\hline$p_{k=7}$ & 0.0174 & 0.0203 & 0.0195 \\
\hline \multicolumn{4}{|c|}{ Total promotion rates } \\
\hline$s_{k=3}$ & 0.1682 & 1.8701 & 0.2082 \\
\hline$s_{k=4}$ & 0.1880 & 0.4100 & 0.1340 \\
\hline$s_{k=5}$ & 0.2117 & 0.4106 & 0.0773 \\
\hline$s_{k=6}$ & 0.0516 & 0.4058 & 0.0319 \\
\hline \multicolumn{4}{|c|}{ Relative cohort sizes (share) } \\
\hline$M_{3}$ & $1.00(24 \%)$ & $1.00(5 \%)$ & $1.00(8 \%)$ \\
\hline$M_{4}$ & $1.41(33 \%)$ & $2.85(15 \%)$ & $2.83(24 \%)$ \\
\hline$M_{5}$ & $0.53(12 \%)$ & $2.34(13 \%)$ & $2.22(19 \%)$ \\
\hline$M_{6}$ & $0.53(13 \%)$ & $3.01(16 \%)$ & $2.79(23 \%)$ \\
\hline$M_{7}$ & $0.77(18 \%)$ & $9.56(51 \%)$ & $3.10(26 \%)$ \\
\hline
\end{tabular}

Table D.2: Estimated External Promotion rates per Grade

\begin{tabular}{|c|c|c|c|}
\hline & \multicolumn{2}{|c|}{ "Uniform" Specification } & \multirow{2}{*}{$\frac{\text { "Triangular" Specification }}{\text { Women }}$} \\
\hline & Men & Women & \\
\hline$P_{4}$ & -0.0004 & -0.0026 & -0.0010 \\
\hline$P_{5}$ & 0.0148 & 0.0028 & 0.0109 \\
\hline$P_{6}$ & 0.0184 & 0.0037 & 0.0152 \\
\hline$P_{7}$ & 0.0268 & 0.0044 & 0.0155 \\
\hline
\end{tabular}

